\title{
Safe and selective monitoring of consecutive side reactions.
}

\author{
Francesco Maestri ${ }^{\mathrm{a}}$, Sabrina Copelli ${ }^{\mathrm{b}}$, Marco Rizzini $^{\mathrm{a}}$, Renato $\operatorname{Rota}^{\mathrm{a},{ }^{*}}$ \\ a Politecnico di Milano, Dip. di Chimica, Materiali e Ingegneria Chimica "G. Natta”, \\ Piazza Leonardo da Vinci, 32 - 20133 Milano - Italy \\ ${ }^{\mathrm{b}}$ Università degli Studi dell’Insubria, Dip. di Scienza e Alta Tecnologia, \\ Via G.B. Vico, 46 - 20100 Varese - Italy \\ *renato.rota@polimi.it, fax: +390223993180
}

\begin{abstract}
$\underline{\text { Abstract }}$
A number of exothermic semibatch (SB) processes of fine chemical industry may undergo selectivity drops because of the triggering of consecutive degradation reactions of an intermediate target product. The rate of such reactions is normally negligible at the operating conditions specified by the chemical recipe; in fact, the selectivity loss occurs typically under upset conditions in which both reactions (that is, the main one and the consecutive one) are triggered.

This undesired event may lead to dangerous temperature rises if the consecutive degradation of the target product is relatively exothermic.

In this work, on the basis of a fully available set of process variables for calculating a suitable Key Performance Index, a simple kinetic free criterion is presented, through which the marginal ignition of a potential dangerous consecutive reaction can be early detected: this allows for a prompt corrective action aimed to suppress the undesired event, hence recovering the process safety and selectivity. The criterion has been validated using literature data about a relevant industrial oxidation reaction of the fine chemical industry: the selective oxidation of 2-octanol to 2-octanone.
\end{abstract}

Keywords:

Semibatch Reactor (SBR); Consecutive side reactions; Safety; Selectivity; X number; Early warning. 


\section{Introduction}

Several processes of the industrial organic chemistry which involve exothermic reactions may undergo selectivity drops because of consecutive reaction paths leading to the further consumption of an intermediate target product ${ }^{1}$.

For a number of such systems, the two involved reactions (that is the main one and the consecutive one) are of the same class (e.g., both oxidations), which typically implies that the consecutive reaction is characterized by a reaction heat either comparable with or even higher than that of the reaction generating the target species.

Moreover there is normally a selectivity gap between the two reactions, according to which the characteristic rate of the undesired degradation is negligible under ordinary operating conditions and either comparable or higher than that of the main one under upset conditions.

In these cases, at relatively low as well as high activation levels, the system behavior can be described by a "single" overall reaction, given by the main one only or by the sum of the main and consecutive reactions respectively.

In this context, dealing with fine chemical and pharmaceutical processes, multiple reactions of polyfunctional substrates should be mentioned ${ }^{2}$, such as the exothermic substitutions of methanol to the halogen atoms in 2,4,6-trichloro 1,3,5-triazine performed in a methanol excess, also used as a solvent. In this system each reaction step is catalyzed by the generated hydrogen chloride, unless it is neutralized by an alkaline species in the reaction mass. Moreover, free hydrogen chloride can react with methanol, hence leading to a potential dangerous temperature and pressure increase in the reaction vessel.

Another important class of reactions is given by the oxidation processes of a number of organic substrates, in which the target species (intermediate) can be further oxidized: among these, the nitric acid oxidation of several alcohols to the corresponding aldehydes or ketones can be mentioned, for which the much more exothermic oxidation of the target product to carboxylic acids can take place ${ }^{3,4}$. 
Performing such reactions in indirectly cooled semibatch reactors (SBRs), the late and sudden triggering of relatively exothermic consecutive reactions can result in a loss of control of the reaction temperature. This can even lead to dangerous overpressures due either to the system volatility or to the gas generating decomposition events if the reaction mass is thermally unstable $e^{5-8}$. In the process safety literature of the last decades ${ }^{9-17}$ a number of criteria have been presented, through which safe and productive operating conditions of single exothermic semibatch reactions can be easily identified.

Such criteria have been also applied to the analysis of multiple reaction systems with consecutive consumption of a target product. For these systems, however, the interaction between the parameters of the two involved reactions makes the development of an unambiguous safety criterion not straightforward $^{18}$.

Moreover, the aforementioned criteria are not suitable for on-going monitoring the safe reactor regime during its normal operation and still require a kinetic characterization of the system. However, such a characterization cannot be economically performed when dealing with fully diversified noncontinuous processes, as those encountered in the fine chemical and pharmaceutical industries.

For this reason, a general kinetic free family of safety criteria has been proposed in the literature ${ }^{19-21}$ which, on the basis of a fully available set of process variables, allows for both identifying the safe operating conditions of exothermic SBRs and monitoring the reactor operation during each batch of an industrial campaign.

In this work the aforementioned criteria have been extended to the monitoring of the safe and selective operation of multiple reactions in semibatch systems, either homogeneous or heterogeneous, in which a consecutive degradation of a target product can take place under upset conditions.

The proposed criterion has been successfully validated through literature data concerning the nitric acid oxidation of 2-octanol to 2-octanone ${ }^{3,4}$. 


\section{Mathematical model}

In order to develop a general criterion for monitoring the safe and selective operation of an indirectly cooled SBR in which an either homogeneous or heterogeneous reaction process of the type:

$v_{\mathrm{A}} \mathrm{A}+\mathrm{v}_{\mathrm{B}} \mathrm{B} \stackrel{1}{\rightarrow} v_{\mathrm{C}} \mathrm{C} \stackrel{2}{\rightarrow} v_{\mathrm{D}} \mathrm{D}$

is carried out, the mathematical model of the reactor must be preliminarily expressed in a suitable dimensionless form.

According to the reaction scheme reported in Eq. (1), C is the intermediate target product, which can undergo a further degradation to an undesired product D through a generic consecutive reaction.

It is assumed that the onset of such a consecutive reaction can occur only once the main one is fully ignited, as a consequence of a selectivity gap existing under normal conditions between the two reactions, allowing for selectively isolating the target product, C.

The mass balance equation for the i-th species in a Semi Batch Reactor (SBR) can be expressed in dimensional form as:

$\frac{\mathrm{dn}_{\mathrm{i}}}{\mathrm{dt}}=\mathrm{F}_{\mathrm{i}, \mathrm{dos}}+\sum_{\mathrm{j}=1}^{\mathrm{NR}} v_{\mathrm{i}, \mathrm{j}} \cdot \mathrm{r}_{\mathrm{j}} \cdot \mathrm{V}_{\mathrm{r}}$

$v_{\mathrm{i}, \mathrm{j}}$ being the stoichiometric coefficient of the i-th species in the j-th chemical reaction (taken as positive or negative if the $\mathrm{i}$-th species in the $\mathrm{j}$-th reaction is a product or a reactant, respectively) and $\mathrm{F}_{\mathrm{i}, \text { dos }}$ being different from zero for A only, that is for the dosed coreactant.

Through simple linear combinations of Equations (2), the following expressions of the concentrations of $\mathrm{A}$ and $\mathrm{B}$ in the SBR during the coreactant dosing can be derived:

$C_{A}=\frac{v_{A}}{v_{B}} \cdot C_{B 0} \cdot \frac{\vartheta-\zeta}{1+\varepsilon \vartheta}$

$\mathrm{C}_{\mathrm{B}}=\mathrm{C}_{\mathrm{B} 0} \cdot \frac{1-\zeta}{1+\varepsilon \vartheta}$

where $\zeta$ is the conversion of the species B (the one initially loaded in the SBR), equal to the ratio of its reacted to initial amount and $\vartheta=\mathrm{t} / \mathrm{t}_{\mathrm{dos}}$ is the dimensionless time. 
Defining $\eta$ as the yield to the target product $C$, equal to the molar ratio between the amount of $\mathrm{C}$ generated and the initial amount of $\mathrm{B}$, the reaction mass composition can be univocally described in terms of $\zeta$ and $\eta$ through the following dimensionless equations:

$\frac{\mathrm{d} \zeta}{\mathrm{d} \vartheta}=\left(\mathrm{v}_{\mathrm{A}} \mathrm{DaRE}\right)_{1} \cdot \mathrm{f} \cdot \kappa_{1}$

$\frac{\mathrm{d} \eta}{\mathrm{d} \vartheta}=\frac{v_{\mathrm{C}}}{v_{\mathrm{B}}} \cdot \frac{\mathrm{d} \zeta}{\mathrm{d} \vartheta}-\left(v_{\mathrm{C}} \mathrm{DaRE}\right)_{2} \cdot \eta \cdot \kappa_{2}$

The initial conditions of the problem state that $\zeta=\eta=0$ at $\vartheta=0$.

Dealing for the sake of example with homogeneous reaction systems of the first order with respect to each reactant, $\left(v_{\mathrm{A}} \text { Da RE }\right)_{1}=v_{\mathrm{A}} \mathrm{k}_{1, \mathrm{R}} \mathrm{t}_{\mathrm{dos}} \mathrm{C}_{\mathrm{B} 0},\left(v_{\mathrm{C}} \text { Da } \mathrm{RE}\right)_{2}=v_{\mathrm{C}} \mathrm{k}_{2, \mathrm{R}} \mathrm{t}_{\mathrm{dos}}$ (that is, with a reactivity enhancement factor, RE, equal to one for both the reactions) and $f=(\vartheta-\zeta) \cdot(1-\zeta) /(1+\varepsilon \vartheta)$.

Once the whole coreactant amount has been dosed, the $\vartheta-\zeta$ and $1+\varepsilon \vartheta$ terms in equations (5) and (6) must be substituted with $1-\zeta$ and $1+\varepsilon$, respectively ${ }^{14}$.

The dimensional form of the energy balance for the SBR provides:

$n \tilde{C}_{P} \cdot \frac{d T}{d t}=\left(F \tilde{C}_{P}\right)_{d o s} \cdot\left(T_{d o s}-T\right)+\sum_{j=1}^{N R} r_{j} \cdot\left(-\Delta \widetilde{H}_{j}\right) \cdot V_{r}-U \cdot A_{H} \cdot\left(T-T_{c o o l}\right)$

where the reaction enthalpy contribution is equal to:

$\dot{\mathrm{Q}}_{\mathrm{r}}=\sum_{\mathrm{j}=1}^{\mathrm{NR}} \mathrm{r}_{\mathrm{j}} \cdot\left(-\Delta \widetilde{\mathrm{H}}_{\mathrm{j}}\right) \cdot \mathrm{V}_{\mathrm{r}}=\frac{\mathrm{n}_{\mathrm{B} 0}}{v_{\mathrm{C}} \cdot \mathrm{t}_{\mathrm{dos}}} \cdot \frac{\mathrm{d} \eta}{\mathrm{d} \vartheta} \cdot\left(-\Delta \widetilde{\mathrm{H}}_{1}\right)+\left(\frac{\mathrm{n}_{\mathrm{B} 0}}{v_{\mathrm{B}} \cdot \mathrm{t}_{\mathrm{dos}}} \cdot \frac{\mathrm{d} \zeta}{\mathrm{d} \vartheta}-\frac{\mathrm{n}_{\mathrm{B} 0}}{v_{\mathrm{C}} \cdot \mathrm{t}_{\mathrm{dos}}} \cdot \frac{\mathrm{d} \eta}{\mathrm{d} \vartheta}\right) \cdot\left(-\Delta \widetilde{\mathrm{H}}_{1}-\Delta \widetilde{\mathrm{H}}_{2}\right)$

Equation (8) can be written, in dimensionless form, as:

$$
\left(1+\mathrm{R}_{\mathrm{H}} \varepsilon \vartheta\right) \cdot \frac{\mathrm{d} \breve{\mathrm{T}}}{\mathrm{d} \vartheta}=\Delta \widetilde{\mathrm{T}}_{\mathrm{ad}, \mathrm{C}} \cdot \frac{v_{\mathrm{B}}}{v_{\mathrm{C}}} \cdot \frac{\mathrm{d} \eta}{\mathrm{d} \vartheta}+\Delta \widetilde{\mathrm{T}}_{\mathrm{ad}, \mathrm{D}} \cdot\left(\frac{\mathrm{d} \zeta}{\mathrm{d} \vartheta}-\frac{v_{\mathrm{B}}}{v_{C}} \cdot \frac{\mathrm{d} \eta}{\mathrm{d} \vartheta}\right)-\varepsilon \cdot\left[\mathrm{Wt} \cdot(1+\varepsilon \vartheta)+\mathrm{R}_{\mathrm{H}}\right] \cdot\left(\widetilde{\mathrm{T}}^{-\breve{\mathrm{T}}_{\text {eff,cool }}}\right)
$$

where the two following adiabatic temperature rises to yield the intermediate target product $\mathrm{C}$ and the final degradation product $\mathrm{D}$ are equal to:

$$
\begin{aligned}
& \Delta \widetilde{\mathrm{T}}_{\mathrm{ad}, \mathrm{C}}=\frac{\mathrm{C}_{\mathrm{B} 0} \cdot\left(-\Delta \widetilde{\mathrm{H}}_{1}\right)}{v_{\mathrm{B}} \cdot \widetilde{\rho} \cdot \widetilde{\mathrm{C}}_{\mathrm{P}} \cdot \mathrm{T}_{\mathrm{R}}} \\
& \Delta \widetilde{\mathrm{T}}_{\mathrm{ad}, \mathrm{D}}=\frac{\mathrm{C}_{\mathrm{B} 0} \cdot\left(-\Delta \widetilde{\mathrm{H}}_{1}-\Delta \widetilde{\mathrm{H}}_{2}\right)}{v_{\mathrm{B}} \cdot \widetilde{\rho} \cdot \widetilde{\mathrm{C}}_{\mathrm{P}} \cdot \mathrm{T}_{\mathrm{R}}}
\end{aligned}
$$


On the basis of the desired reaction product between $\mathrm{C}$ and $\mathrm{D}$, two target operating conditions of the SBR can be defined.

If the target species is the intermediate product $\mathrm{C}$, the safe SBR operation corresponds to a regime under which the dosed coreactant is consumed by the main reaction at a much lower time scale than that at which it is fed ${ }^{9,14}$; moreover, the characteristic time of the consecutive degradation reaction is much higher than any other time scale involved in the process. The system behavior can therefore be described by a single reaction, corresponding to the main one ${ }^{4}$.

According to the first condition, a pseudo steady state assumption on the unreacted coreactant amount in the SBR can be stated, so that:

$\frac{\mathrm{d} \zeta}{\mathrm{d} \vartheta} \cong 1$

The second condition implies instead that:

$\frac{\mathrm{d} \eta}{\mathrm{d} \vartheta} \cong \frac{v_{\mathrm{C}}}{v_{\mathrm{B}}}$

This means that under target operating conditions of the SBR aimed to isolate the intermediate product $\mathrm{C}$, both the conversion of $\mathrm{B}, \zeta$, and the yield to $\mathrm{C}, \eta$, are proportional during the supply period to the fraction of the dosing time. The involved proportionality factors are respectively equal to one for the conversion $\zeta$ and to the ratio of the stoichiometric coefficients of $\mathrm{C}$ in the consecutive reaction and of $\mathrm{B}$ in the main one for the yield $\eta$.

Substituting equations (12) and (13) in the expression (8) of the whole reaction enthalpy contribution, we get:

$\dot{\mathrm{Q}}_{\mathrm{r}, \mathrm{ta}_{\mathrm{C}}} \cong \frac{\mathrm{n}_{\mathrm{B} 0}}{\mathrm{v}_{\mathrm{B}} \cdot \mathrm{t}_{\mathrm{dos}}} \cdot\left(-\Delta \widetilde{\mathrm{H}}_{1}\right)=\frac{\mathrm{F}_{\mathrm{A}, \mathrm{dos}}}{v_{\mathrm{A}}} \cdot\left(-\Delta \widetilde{\mathrm{H}}_{1}\right)$

where the label tac identifies indeed the target conditions aimed to isolate C.

Moreover, under target operating conditions for an exothermic SBR, the characteristic time of the reaction heat removal is, in any case, much lower than that of the reaction heat contribution. This is consistent with a pseudo state steady state behavior of the reaction temperature ${ }^{9,14}$ : 
$\frac{\mathrm{d} \breve{\mathrm{T}}}{\mathrm{d} \vartheta} \cong 0$

Substituting equations (12), (13) and (15) in the energy balance equation (9), the following expression of the target temperature profile can be obtained, valid for fully selective operating conditions aimed to isolate $\mathrm{C}$ :

$\breve{\mathrm{T}}_{\mathrm{ta}}=\widetilde{\mathrm{T}}_{\mathrm{eff}, \text { cool }}+\frac{1.05 \Delta \breve{\mathrm{T}}_{\mathrm{ad}, \mathrm{C}}}{\varepsilon \cdot\left[\mathrm{Wt} \cdot(1+\varepsilon \vartheta)+\mathrm{R}_{\mathrm{H}}\right]}$

In Equation (16) the 1.05 coefficient takes into account the deviation of the real SBR regime from the theoretical target conditions ${ }^{9,14}$.

If the target species is the final degradation product $\mathrm{D}$, the safe SBR operation still corresponds to a regime under which the dosed coreactant is converted at a much lower time scale than that at which it is fed ${ }^{9,14}$. Nevertheless, at the same time, the target product $C$ is consumed by the consecutive reaction at a much lower time scale than that at which it is generated. Also in this case the system behaves as a single reaction one ${ }^{4}$, corresponding however to the one-step fully unselective production of the final degradation species, D. This implies that the amounts of both the unreacted coreactant $\mathrm{A}$ and the intermediate species C in the SBR quickly reach a pseudo steady state value.

Under these conditions, approximation (12) still holds true, whereas expression (13) modifies as follows:

$\frac{\mathrm{d} \eta}{\mathrm{d} \vartheta} \cong 0$

Substituting equations (12) and (17) in the expression (8) of the whole reaction enthalpy contribution, we get:

$\dot{\mathrm{Q}}_{\mathrm{r}, \mathrm{ta}_{\mathrm{D}}} \cong \frac{\mathrm{n}_{\mathrm{B} 0}}{v_{\mathrm{B}} \cdot \mathrm{t}_{\mathrm{dos}}} \cdot\left(-\Delta \widetilde{\mathrm{H}}_{1}-\Delta \widetilde{\mathrm{H}}_{2}\right)=\frac{\mathrm{F}_{\mathrm{A}, \mathrm{dos}}}{v_{\mathrm{A}}} \cdot\left(-\Delta \widetilde{\mathrm{H}}_{1}-\Delta \widetilde{\mathrm{H}}_{2}\right)$

where the label ta identifies indeed the target conditions aimed to produce $\mathrm{D}$ at full yield.

Moreover, under such conditions the SBR temperature time profile approaches the following target one:

$\breve{\mathrm{T}}_{\mathrm{ta}_{\mathrm{D}}}=\breve{\mathrm{T}}_{\text {eff,cool }}+\frac{1.05 \Delta \breve{\mathrm{T}}_{\mathrm{ad}, \mathrm{D}}}{\varepsilon \cdot\left[\mathrm{Wt} \cdot(1+\varepsilon \vartheta)+\mathrm{R}_{\mathrm{H}}\right]}$ 


\section{Safe and selective SBR operation}

Dealing with relatively fast and exothermic reaction systems of the type expressed by Eq. (1), that is undergoing a potential consecutive degradation of an intermediate target product, a laboratory semibatch recipe must be formerly developed, which identifies process conditions where the ignition of the undesired consecutive reaction is negligible.

In particular, the selectivity gap between the two involved reactions can be measured through the following parameter:

$\mathrm{S}=\frac{\left(v_{\mathrm{A}} \mathrm{DaRE}\right)_{1}}{\left(v_{\mathrm{C}} \mathrm{DaRE}\right)_{2}}$

normally reaching relatively high values within the allowed temperature range.

On the basis of the laboratory recipe, a coreactant dosing time can then be estimated at the industrial scale, which is much higher than the characteristic time of the coreactant consumption by the main reaction: this can be performed even without a kinetic characterization of the system ${ }^{19-21}$.

Moreover, under selective operating conditions, the characteristic time of the consecutive degradation of the target product is much higher than any other time scale involved in the process.

For these reasons the SBR operation is, at the limit, independent on the kinetics of the reactions involved $^{19-21}$, being the characteristic time of the main reaction, at the limit, equal to the dosing time and that of the consecutive degradation reaction theoretically infinite.

Dealing with isoperibolic SBRs, the characteristic time of the main reaction undergoes a decrease in the first part of the dosing period because of the reaction temperature rise, and a final increase because of the consumption of the reactant B initially loaded in the SBR.

In any case, for most of the dosing period it can be assumed that the coreactant accumulation is kept at relatively low values.

Instead, depending on the activation parameter:

$K=\frac{E_{a c t, 2}}{E_{a c t, 1}}$ 
the consecutive reaction can undergo an acceleration during the coreactant supply higher than that of the main one, taking also into account that the intermediate product $\mathrm{C}$ (which is indeed the reactant of the consecutive reaction) accumulates in the system.

Consequently, operating the SBR under initial Quick Onset, Fair Conversion, Smooth Temperature Profile (in the following referred to as QFS) conditions with respect to the main reaction ${ }^{9,14}$, the triggering of the consecutive degradation, if it occurs at a relevant extent, is typically superimposed to that of the main one, as a consequence of the selectivity gap normally existing between the two reactions.

Therefore, dealing with such reaction processes, even operating the SBR at a minimum accumulation of the dosed coreactant, the thermal loss of control of the system can occur as well as a result of the late sudden triggering of a relatively exothermic degradation of the intermediate product, whose onset must be therefore early detected.

In particular, the higher the enthalpy parameter:

$\Phi=\frac{\Delta \widetilde{\mathrm{H}}_{2}}{\Delta \widetilde{\mathrm{H}}_{1}}$

is, the more and more severe are the consequences of such a scenario.

Whereas the control of the main reaction can be kept by operating the SBR at a sufficiently low coreactant accumulation, runaway phenomena due to the consecutive degradation reaction can be prevented only suppressing it all along the duration of the process ${ }^{22-25}$.

However, a number of incidental deviations from the aforementioned safe and selective operating conditions can occur during a production campaign, some of which can be directly recognized through normally monitored process variables and some cannot ${ }^{26}$.

Failures of the temperature control system of the reactor typically belong to the former category of scenarios. In this case the reaction is performed at too high temperatures, at which both the reactions are activated with a consequent selectivity loss and, in some cases, with the risk of a thermal runaway ${ }^{5}$. 
In the second category, unexpected catalytic effects of impurities (coming from either the plant or the raw materials) are included; particularly, they can trigger the consecutive degradation reaction at temperatures at which its ignition level should be negligible. In other cases, anomalous $\mathrm{pH}$ variations during the reaction could have a catalytic effect on the undesired reaction ${ }^{5}$.

Facing the latter type of scenarios, it is of particular importance monitoring the SBR operation through a simple and general criterion which, on the basis of fully available process variables, allows for promptly detecting the triggering of a side consecutive reaction.

The onset of such a side reaction can be classified as marginal, runaway, or instantaneous. In the first case, as the target intermediate species accumulates in the SBR, its further decomposition is only marginally triggered: therefore, even if it were not detected, it could not cause a significant degradation of the target product.

In the second case, the degree of ignition of the consecutive reaction is sufficient to trigger a short time scale degradation of the target product with the evolution of the related heat of reaction. Such an unexpected onset, typically occurring at relatively high accumulation levels of the intermediate species, can lead to dangerous temperature peaks, depending on the $\Phi$ parameter value.

In the last case, the onset of both the reactions occurs starting from the earliest fractions of the dosing period, so that the generated amount of $\mathrm{C}$ is quickly consumed at a much lower time scale: in this scenario the SBR can be still operated under thermal control conditions, but the process is fully unselective.

When dealing with single reaction systems, suitable Key Process Parameters (KPIs) can be defined on the basis of available process variables, through which the full ignition operation of the SBR can be on-going detected ${ }^{19-21}$.

Dealing with a reaction system of the type expressed by Eq. (1), either homogeneous or heterogeneous, once QFS operating conditions for the SBR have been identified in the range where only the main reaction is ignited, the $\mathrm{X}$ parameter is defined $\mathrm{as}^{21}$ :

\section{DOI: 10.1021/acs.iecr.7b02989}


$\mathrm{X}=\frac{\left(\mathrm{m} \widehat{\mathrm{C}}_{\mathrm{P}}\right)_{0} \cdot\left(\mathrm{T}-\mathrm{T}_{0}\right)+\left(\mathrm{m} \widehat{\mathrm{C}}_{\mathrm{P}}\right)_{\mathrm{fed}} \cdot\left(\mathrm{T}-\mathrm{T}_{\mathrm{dos}}\right)+\int_{0}^{\mathrm{t}}\left(\dot{\mathrm{m}} \cdot \widehat{\mathrm{C}}_{\mathrm{P}} \cdot \Delta \mathrm{T}\right)_{\text {cool }} \mathrm{dt}}{\left(-\Delta \widehat{\mathrm{H}}_{\mathrm{r}}\right) \cdot \mathrm{m}_{\mathrm{fed}} \cdot \omega_{\mathrm{A}} / v_{\mathrm{A}}} \cdot 100$

It should be stressed again that the $\mathrm{X}$ number measurement does not require any kinetic characterization of the system, but only the much more straightforward estimation of the reaction heat $^{21}$. All the other variables involved in equation (23) come from on-line plant measurements, such as temperatures of mass flowrates.

The calculation of $\mathrm{X}$ according to equation (23) is intended to be performed after the coreactant dosing has been started ${ }^{21}$, that is, for $\mathrm{t}>0$ since at $\mathrm{t}=0$ expression (23) is indeterminate from a mathematical point of view and the semibatch reaction system is not triggered from a physical point of view.

The $\mathrm{X}$ parameter, previously proposed for monitoring the safe development of a single reaction process, is also useful for ongoing detecting the triggering of the consecutive degradation of the target product, provided that its thermal effects are not negligible even at the lower reaction extents.

In fact, when the consecutive side reaction is negligibly ignited the $\mathrm{X}$ number defined by Eq. (23) corresponds to the conversion degree of the dosed coreactant ${ }^{21}$. In this case, the X number quickly reaches values close to 100 , that cannot be overcome. If an even marginal triggering of a consecutive exothermic event took place, once X has quickly reached values close to 100 (as a consequence of QFS conditions for the main reaction) its trend would not stabilize but would continuously increase above the aforementioned upper limit due to the thermal contribution of the consecutive side reaction. Such a behavior allows for discriminating between the heat effects of the two reactions, provided that a satisfactory selectivity gap exists between them under normal operating conditions.

In Figures 1 to 4 typical time profiles of the dimensionless variables $\zeta, \eta$ and $\widetilde{T}$ at increasing initial temperatures are plotted, for a system in which the heats of the two involved reactions are equal (that is for $\Phi=1)$.

Figure 1 refers to non-ignition operating conditions, that is, to operating conditions where the coolant temperature is too low for triggering even the main reaction, as evident from Figure 1A (showing very low values of both conversion and yield) and 1B (showing temperature values well below the

\section{DOI: 10.1021/acs.iecr.7b02989}


target profile for the desired reaction product C). In this case the X parameter (shown in Figure 1C) never approaches the required value equal to 100 .

As expected, under safe and selective operating conditions (Figure 2) both conversion and yield time profiles are close to each other and the SBR temperature quickly approaches the target C profile expressed by Eq. (16). In this case the X parameter (shown in Figure 2C) quickly approaches the required value equal to 100 . Note that this figure reports two curves for the $\mathrm{X}$ profile, labelled "Measured profile” and "Calculated profile”, respectively. As a matter of fact, both profiles are calculated. In particular, the first one ("Measured profile”) is derived using equation (23) and the computed values of temperature (that is, it represents the values that would be measured during the online monitoring of the process). The second one ("Calculated profile") is instead the calculated conversion degree of the dosed coreactant:

$\chi=\frac{\zeta}{\vartheta} \cdot 100$

which equals the $\mathrm{X}$ number only when the consecutive side reaction is fully inhibited; therefore, it represents the expected value of the $\mathrm{X}$ number under fully selective conditions.

As shown in Figures $3 \mathrm{~A}$ and $3 \mathrm{~B}$, further increasing the cooling temperature leads to ignited and marginally unselective operating conditions characterized by a huge final yield loss (that is, 30\%). Such a decay is however only marginally detected by the reaction temperature, slightly overcoming the target $\mathrm{C}$ profile: in particular, for a reference temperature equal to $300 \mathrm{~K}$, the maximum expected difference between the real and target temperatures would be of only $3^{\circ} \mathrm{C}$. Instead, as can be recognized from Figure 3C, a X number anomalous increase above 100 can be detected yet at the 25\% of the supply period, reaching 110 at half dosing, where the yield loss is still less than 5\%.

This behavior clearly shows that the $\mathrm{X}$ parameter can be used also for promptly detecting the triggering of a side consecutive reaction, even when the heats of the two involved reactions are similar (that is, for $\Phi \cong 1$ as for Figure 3). At higher $\Phi$ values the triggering of the consecutive reaction can instead lead to huge temperature rises above both the target profiles expressed by Eqs. (16) and (19), 
with a sudden transition between the two involved reactions, as represented in Figure 5. In any case, monitoring the $\mathrm{X}$ value allows for promptly detecting the undesired scenario and adopting the process actions aimed to suppress it.

Ignited and fully unselective operating conditions (shown in Figure 4) arise from a higher cooling temperature and further confirm the aforementioned conclusions: conversion increases almost linearly with time, while yield drops down to very low values. The temperature profile quickly approaches the target value for the unwanted $\mathrm{D}$ product and $\mathrm{X}$ quickly overcomes the upper bound value of 100 .

Therefore summarizing, the $\mathrm{X}$ parameter compares the effective energy increase of the initial reaction mass, of the dosed mass, and of the coolant with a target energy amount coming from the complete and selective conversion of the dosed coreactant, due to the main reaction only ${ }^{21}$. If an exothermic side consecutive reaction takes place with not negligible energy effects, the $\mathrm{X}$ number undergoes an anomalous increase above 100.

The effectiveness of the proposed criterion is directly related to the $\Phi$ parameter expressed by Eq. (22). The higher $\Phi$ is, the earlier the activation of the consecutive reaction through $\mathrm{X}$ can be detected: such a behavior is welcome, since at relatively high $\Phi$ values, a more severe impact of the thermal loss of control of the consecutive reaction corresponds, whose triggering should therefore be earlier detected.

Instead, if $\Phi$ is relatively small, the heat effects of the consecutive reaction are, at the limit, negligible and therefore an even significant selectivity drop due to its ignition cannot be detected through the described method. On the other hand, if $\Phi$ reaches too high values, the energy effects of the consecutive reaction would be significant even at negligible extents of the target product degradation. This would therefore trigger undue corrective actions, even under nearly selective operating conditions. However, for a number of reactions of the same class, the heat effects of both the reactions are of the same order of magnitude, so that $\Phi$ parameters between 1 and 10 can be expected. 
For what concerns a robust application of the criterion, false alarms arising from the measured $\mathrm{X}$ number fluctuations must be effectively minimized. To this aim, it is advisable, at the industrial scale, to limit the measurement noise of the original process variables, on the basis of which $\mathrm{X}$ is calculated. Such a goal can be reached, as discussed elsewhere ${ }^{19}$, adopting a redundancy of the temperature detectors, being the accuracy of the modern flowmeters typically better than $0.2 \%$. In this way, the aforementioned X number fluctuations can be effectively smoothed. Moreover, it must be taken into account that $\mathrm{X}$ is an integral process parameter, which, for this reason, is intrinsically less sensitive to statistical measurement errors of the original process variables.

Once a X number trend overcoming 100 is detected, the safe and selective SBR operation can be in most cases recovered through a rapid thermal quench of the reaction mass, directly influencing the activation degree of both chemical reactions ${ }^{22-25}$.

In order to make such a corrective action even prompter, a simultaneous interruption of the coreactant feed could be triggered, so that the exothermic contribution of the main reaction disappears and the reactor cooling is consequently faster.

Moreover, depending on the chemical characteristics of any reaction system, once an uncontrolled X number rise is detected, even more targeted corrective actions can be adopted: for the sake of example, the chemical quench of the system through inhibitor shots or the bottom venting of the reaction mass to an unconfined quench pool can be mentioned.

\section{Case study: nitric acid oxidation of 2-octanol}

The proposed criterion has been validated through literature data concerning an oxidation process of the fine chemical industry, that is the nitric acid oxidation of 2-octanol to 2-octanone ${ }^{3,4}$.

The reaction is performed in an indirectly cooled SBR, in which 2-octanol (A) is dosed at temperatures slightly below $-10^{\circ} \mathrm{C}$ and under intensive stirring over an aqueous nitric acid reaction phase. Before starting the coreactant feed, a catalytic amount of sodium nitrite, $\mathrm{NaNO}_{2}$, is added in one shot to the reaction mass. Sodium nitrite instantaneously reacts with nitric acid, generating an

\section{DOI: 10.1021/acs.iecr.7b02989}


equivalent amount of nitrosonium ion, $\mathrm{NO}^{+}$, which is the active species (B) oxidizing the original alcohol, according to the following autocatalytic scheme ${ }^{3}$ :

$\mathrm{A}+\mathrm{B} \stackrel{\text { nol }}{\rightarrow} \mathrm{P}+2 \mathrm{~B}$

$\mathrm{P}+\mathrm{B} \stackrel{\text { none }}{\longrightarrow} \mathrm{CX}$

As can be noticed from the reaction path above, 2-octanone (P) can be further oxidized under upset conditions to unwanted carboxylic acids (CX).

In Table 1 the relevant physical properties of the two involved liquid phases are summarized.

Moreover, from the data reported in Table 2, it can be calculated that the consecutive oxidation reaction is 3.25 times more exothermic than the main one, so that its sudden triggering can lead to the thermal loss of control of the SBR.

Provided that an effective stirring of the reaction mass is kept all along the process, the mass transfer resistances have a negligible influence on the overall conversion rate, so that the SBR operates in the slow reaction regime.

On this basis, the SBR behavior can be simulated solving the following set of mass and energy balance equations ${ }^{4}$ :

$\frac{d \xi_{\mathrm{P}}}{\mathrm{d} \vartheta}=\mathrm{m}_{\mathrm{A}} \cdot \mathrm{k}_{\mathrm{nol}} \cdot \mathrm{t}_{\mathrm{dos}} \cdot \mathrm{C}_{\mathrm{A}, \mathrm{dos}} \cdot\left(\vartheta-\xi_{\mathrm{P}}-\xi_{\mathrm{CX}}\right) \cdot \frac{\xi_{\mathrm{B} 0}+\xi_{\mathrm{P}}}{\vartheta}-\frac{\mathrm{d} \xi_{\mathrm{CX}}}{\mathrm{d} \vartheta}$

$\frac{\mathrm{d} \xi_{\mathrm{CX}}}{\mathrm{d} \vartheta}=\mathrm{m}_{\mathrm{P}} \cdot \mathrm{k}_{\mathrm{none}} \cdot \mathrm{t}_{\mathrm{dos}} \cdot \mathrm{C}_{\mathrm{A}, \mathrm{dos}} \cdot \xi_{\mathrm{P}} \cdot \frac{\xi_{\mathrm{B} 0}+\xi_{\mathrm{P}}}{\vartheta}$

$\frac{\mathrm{dT}}{\mathrm{d} \vartheta}=\frac{1}{\left(1+\mathrm{R}_{\mathrm{H}} \varepsilon \vartheta\right)}\left\{\Delta \mathrm{T}_{\mathrm{ad}, \mathrm{P}} \cdot \frac{\mathrm{d} \xi_{\mathrm{P}}}{\mathrm{d} \vartheta}+\Delta \mathrm{T}_{\mathrm{ad}, \mathrm{CX}} \cdot \frac{\mathrm{d} \xi_{\mathrm{CX}}}{\mathrm{d} \vartheta}-\varepsilon \cdot\left[\mathrm{Wt} \cdot(1+\varepsilon \vartheta)+\mathrm{R}_{\mathrm{H}}\right] \cdot\left(\mathrm{T}-\mathrm{T}_{\text {eff,cool }}\right)\right\}$

where $\xi_{\mathrm{P}}$ and $\xi_{\mathrm{CX}}$ are the 2-octanone (P) and carboxylic acids (CX) amounts referred to the overall amount of 2-octanol (A) to be dosed, and:

$\mathrm{k}_{\mathrm{nol} / \mathrm{none}}=\mathrm{k}_{\infty, \text { nol } / \text { none }} \cdot \exp \left(-\frac{\mathrm{E}_{\text {nol } / \text { none }}}{\mathrm{RT}}-\mathrm{m}_{\mathrm{H} \mathrm{n}_{\text {nol } / \text { none }}} \cdot \mathrm{H}_{0}\right)$

After the dosing period, the $\vartheta-\xi_{\mathrm{P}}-\xi_{\mathrm{CX}}$ and $\varepsilon \vartheta$ terms in equations (26) to (28), must be respectively replaced with $1-\xi_{\mathrm{P}}-\xi_{\mathrm{CX}}$ and $\varepsilon$. 
Moreover, the initial conditions state that at $\vartheta=0, \xi_{\mathrm{P}}=\xi_{\mathrm{CX}}=0$ and $\mathrm{T}=\mathrm{T}_{0}$, whereas the operating parameters of the simulated SBR are listed in Table 3.

The kinetic parameters in equation (29) are summarized in Table 2, where also the heats of the two reactions are reported.

As can be noticed from equations (29), the oxidation rates are strongly influenced by the acidic strength of the reaction phase, which is expressed by the following functional dependence of the Hammet's acidity function on the nitric acid mass fraction ${ }^{4}$ :

$\mathrm{H}_{0}=-0.0545 \times \mathrm{wt}_{\%, \mathrm{HNO}_{3}}-0.1825\left(10 \leq \mathrm{wt}_{\%, \mathrm{HNO}_{3}} \leq 70\right)$

$\mathrm{H}_{0}=-0.1228 \times \mathrm{wt}_{\%, \mathrm{HNO}_{3}}-0.5 \quad\left(0 \leq \mathrm{wt}_{\%, \mathrm{HNO}_{3}} \leq 10\right)$

In equation (30) the mass percentage of nitric acid in the aqueous reaction phase, $w t_{\%, H N O_{3}}$, is related to $\xi_{\mathrm{P}}$ and $\xi_{\mathrm{CX}}$ through the following expression:

$$
\mathrm{wt}_{\%, \mathrm{HNO}_{3}}=\frac{\mathrm{n}_{\mathrm{N} 0}-\mathrm{n}_{\mathrm{A} 1} \cdot\left(\xi_{\mathrm{B} 0}+\xi_{\mathrm{P}}+2 \xi_{\mathrm{CX}}\right)}{\mathrm{V}_{\mathrm{r} 0}} \times \frac{\mathrm{M}_{\mathrm{W}, \mathrm{HNO}_{3}}}{\hat{\rho}_{\mathrm{c}}} \times 100
$$

where $\mathrm{M}_{\mathrm{W}, \mathrm{HNO}_{3}}=63 \mathrm{~g} / \mathrm{mol}$ is the molecular weight of nitric acid and $\mathrm{n}_{\mathrm{N} 0}$ is the initial molar amount of nitric acid loaded in the reactor.

Under fully selective operating conditions, the mass balance equation for 2-octanone (P) simplifies to:

$\mathrm{n}_{\mathrm{A} 1} \cdot \frac{\mathrm{d} \xi_{\mathrm{P}}}{\mathrm{dt}}=\mathrm{r}_{\mathrm{eff,nol}} \cdot \mathrm{V}_{\mathrm{r}}$

Substituting equation (32) in the dimensional energy balance equation for the SBR and integrating the resulting equation through the procedure described elsewhere ${ }^{21}$, the following expression of $\xi_{\mathrm{P}}$ can be derived:

$\xi_{\mathrm{P}}=\frac{\left(\mathrm{n} \widetilde{\mathrm{C}}_{\mathrm{P}}\right)_{0} \cdot\left(\mathrm{T}-\mathrm{T}_{0}\right)+\left(\mathrm{n} \widetilde{\mathrm{C}}_{\mathrm{P}}\right)_{\mathrm{fed}} \cdot\left(\mathrm{T}-\mathrm{T}_{\mathrm{dos}}\right)+\int_{0}^{\mathrm{t}} \mathrm{U} \cdot \mathrm{A} \cdot\left(\mathrm{T}-\mathrm{T}_{\mathrm{cool}}\right) \mathrm{dt}}{\mathrm{n}_{\mathrm{A} 1} \cdot\left(-\Delta \widetilde{\mathrm{H}}_{\mathrm{nol}}\right)}$

where $\mathrm{U} \cdot \mathrm{A}_{\mathrm{H}} \cdot\left(\mathrm{T}-\mathrm{T}_{\text {cool }}\right) \approx\left(\dot{\mathrm{m}} \cdot \widehat{\mathrm{C}}_{\mathrm{P}} \cdot \Delta \mathrm{T}\right)_{\text {cool }}$ in terms of measurable process variables.

Moreover, under fully selective QFS operating conditions the 2-octanone (P) molar amount is at the limit proportional to the dosed fraction of 2-octanol (A), so that: 
$\xi_{\mathrm{P}, \mathrm{ta}}=\vartheta$

Dividing equation (33) by equation (34) and expressing the resulting ratio in percentage terms, the $\mathrm{X}$ number expressed by Eq. (23) can be derived also for the autocatalytic system in question.

Moreover, defining the 2-octanol (A) conversion as the percentage ratio of its reacted to fed amounts and taking into account that under fully selective conditions the reacted 2-octanol (A) equals the generated amount of 2-octanone (P), we get:

$\chi=\frac{\mathrm{n}_{\mathrm{P}}}{\mathrm{n}_{\mathrm{A}, \mathrm{fed}}} \cdot 100=\frac{\mathrm{n}_{\mathrm{P}}}{\mathrm{n}_{\mathrm{A} 1 \cdot \vartheta} \cdot 100}=\frac{\xi_{\mathrm{P}}}{\vartheta} \cdot 100=\mathrm{X}$

Therefore, also for the reaction system in question, the $\mathrm{X}$ number equals under selective operating conditions the conversion degree of the dosed 2-octanol (A).

In Figures 6 to 11 the time profiles of $\xi_{\mathrm{P}}$ and $\xi_{\mathrm{CX}}$, of the reaction temperature and of the $\mathrm{X}$ number (23) compared with the calculated 2-octanol (A) conversion (35) are reported for different cooling temperatures and dosing times. The resulting scenarios correspond to: ignited and fully selective, uncontrolled reaction transition, ignited and fully unselective, ignited and fully selective, gradual reaction transition and ignited and fully unselective reactor regimes, respectively.

In particular, Figures 6 to 8 refers to cooling temperature values equal to $-10,0$, and $10{ }^{\circ} \mathrm{C}$ with a 2octanol (A) dosing time of 10 h, while Figures 9 to 11 refers to the same cooling temperature values with a dosing time of $20 \mathrm{~h}$. In the second case, even when the further oxidation of 2-octanone (P) to carboxylic acids (CX) takes place, the SBR cooling efficiency is so high that the reaction temperature is always limited between the target temperatures of 2-octanone (P) and carboxylic acids (CX):

$\mathrm{T}_{\mathrm{ta}_{\mathrm{P} / \mathrm{CX}}}=\mathrm{T}_{\mathrm{eff}, \mathrm{cool}}+\frac{1.05 \Delta \mathrm{T}_{\mathrm{ad}, \mathrm{P} / \mathrm{CX}}}{\varepsilon \cdot\left[\mathrm{Wt} \cdot(1+\varepsilon \vartheta)+\mathrm{R}_{\mathrm{H}}\right]}$

respectively ${ }^{4}$. Such conditions, in which no temperature overshoots above $\mathrm{T}_{\mathrm{ta}, \mathrm{CX}}$ can occur, are referred to as inherently safe operating conditions ${ }^{4}$.

Looking at the trends of Figures 6C to 11C, it can be noticed that under safe and selective process conditions $\mathrm{X}$ number values lower than 100 are always measured. However, in this case a range 70 100 has been evidenced because as the extent of the involved reactions increases, their characteristic 
rates undergo a relevant decrease due (among the others) to the weakening of the acidic reaction phase. This comes from both the nitric acid consumption and the dilution of the acidic reaction phase by the generated water. Such a behavior highlights that, when consecutive side reactions are involved, the acceptable range of the $\mathrm{X}$ parameter should be identified through suitable experiments in a laboratory scale reactor.

As can be noticed from Figures 6C to 11C, in all the simulated scenarios the $\mathrm{X}$ number measurement through fully available process variables allows for early detecting the even marginal energy contribution of the consecutive oxidation reaction. Therefore it allows for a prompt triggering of process corrective actions aimed to recover the process safety and selectivity.

\section{5. $\underline{\text { Conclusions }}$}

A number of runaway scenarios of the fine chemical industry are caused by multiple reaction systems in which an intermediate target species is consumed by a consecutive reaction.

In many cases, the triggering of such reaction can occur only under fully ignited conditions of the main one: this happens for the sake of example when the reactions involved are of the same class.

In this work a general kinetic free criterion has been presented which, on the basis of an univocal and easy to measure process parameter, allows for promptly detecting the even marginal ignition of relatively exothermic and hence dangerous consecutive events. This allows for triggering the proper corrective actions aimed to recover the process safety.

The criterion has been finally validated simulating the behavior of a potential runaway reaction system of the fine chemical industry, that is the nitric acid oxidation of 2-octanol to 2-octanone with further degradation of the target product to unwanted carboxylic acids.

\section{DOI: 10.1021/acs.iecr.7b02989}




\section{Nomenclature}

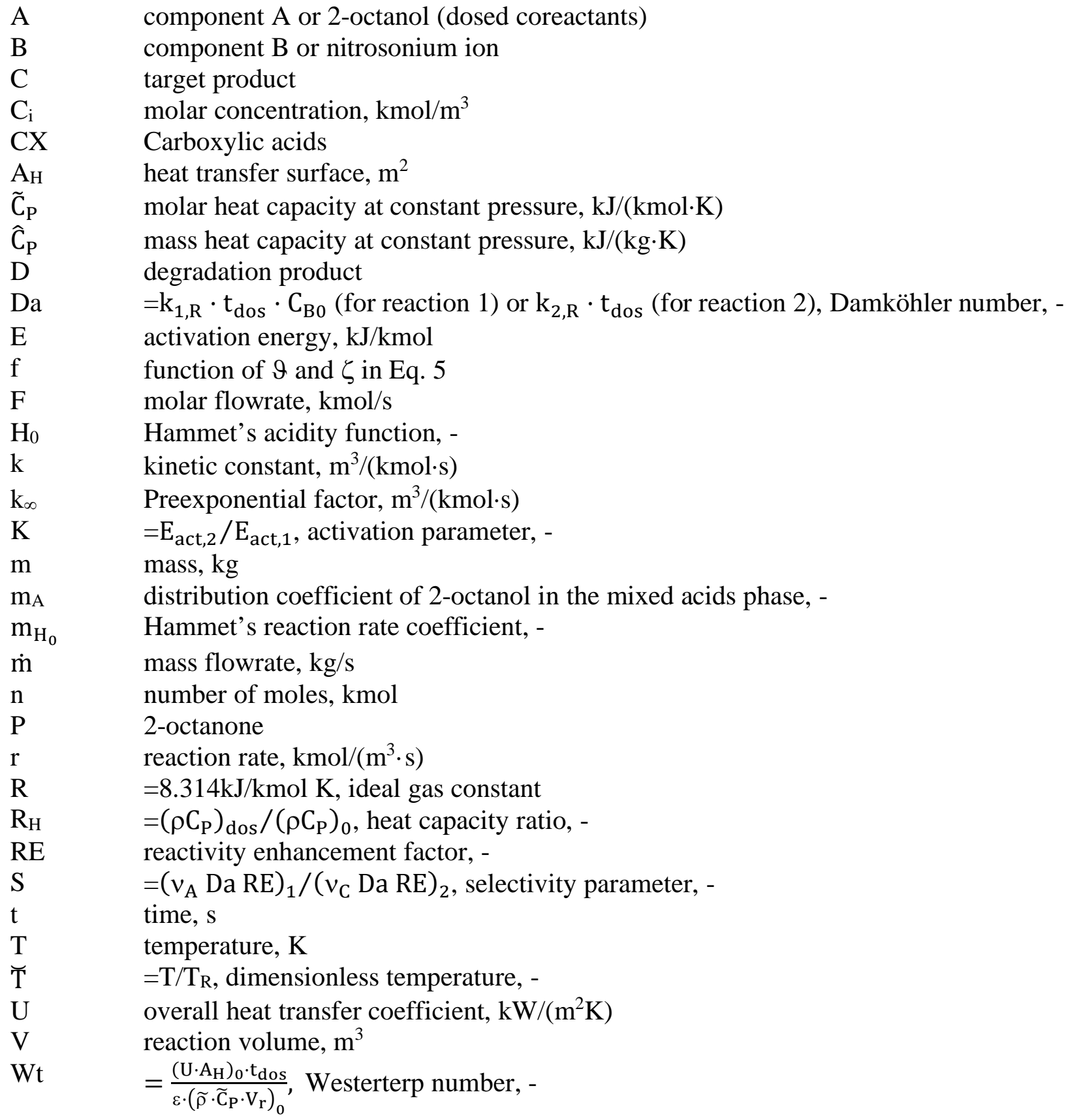

\section{Subscripts and superscripts}

$\begin{array}{ll}\text { ad } & \text { adiabatic } \\ \text { A } & \text { component A or 2-octanol (dosed coreactants) } \\ \text { B } & \text { component B or nitrosonium ion } \\ \text { C } & \text { target product } \\ \text { CX } & \text { carboxylic acids } \\ \text { cool } & \text { coolant } \\ \text { D } & \text { degradation product } \\ \text { dos } & \text { dosing stream or dosing time } \\ \text { eff } & \text { effective }\end{array}$




$\begin{array}{ll}\text { fed } & \text { fed } \\ \mathrm{i} & \begin{array}{l}\text { i-th component } \\ \mathrm{j}\end{array} \\ \mathrm{N} & \text { j-th reaction } \\ \text { nol } & \text { nitric acid } \\ \text { none } & \text { 2-octanol oxidation reaction } \\ \mathrm{NR} & \text { 2-octanone oxidation reaction } \\ \mathrm{P} & \text { number of reactions } \\ \mathrm{r} & \text { 2-octanone } \\ \mathrm{R} & \text { reaction } \\ \text { ta } & \text { reference } \\ 0 & \text { target } \\ 1 & \text { start of the semibatch period } \\ 2 & \text { end of the semibatch period or main reaction } \\ & \text { consecutive reaction }\end{array}$

Greek symbols

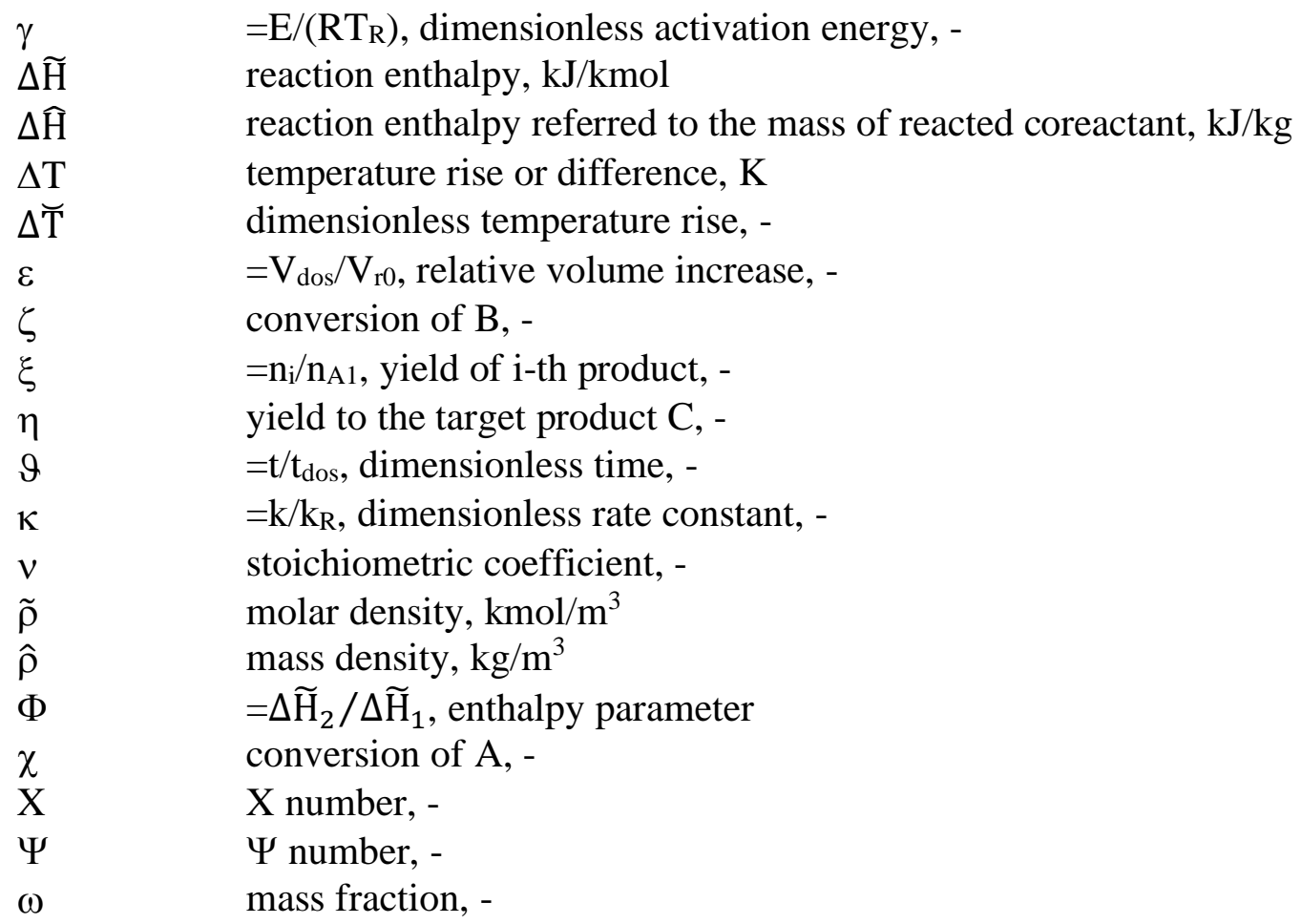




\section{$\underline{\text { References }}$}

(1) Arpe, H. J. Industrial Organic Chemistry; Fifth Ed., Wiley-VCH, Weinheim, 2010.

(2) Smith, M., March, J. Advanced Organic Chemistry: Reactions, Mechanisms and Structure; Sixth Ed., Wiley, New York, 2007.

(3) van Woezik, B. A. A.; Westerterp K. R. The nitric acid oxidation of 2-octanol. A model reaction for multiple heterogeneous liquid-liquid reactions. Chem. Eng. Process. 2000, 39, 521.

(4) van Woezik, B. A. A.; Westerterp K. R. Runaway behavior and thermally safe operation of multiple liquid-liquid reactions in the semibatch reactor. The nitric acid oxidation of 2-octanol. Chem. Eng. Process. 2001, 41, 59.

(5) Cardillo, P. Incidenti in Ambiente Chimico. Guida allo studio e alla valutazione delle reazioni fuggitive; Stazione Sperimentale per i Combustibili: San Donato Milanese, 1998.

(6) Valdes, O. J. R.; Casson Moreno, V.; Waldram, S. P.; Véchot, L. N.; Mannan, M. S. Experimental sensitivity analysis of the runaway severity of Dicumyl peroxide decomposition using adiabatic calorimetry. Thermochimica Acta 2015, 617, 28.

(7) Casson Moreno, V.; Battaglia, E.; Maschio, G. Hydrogen peroxide decomposition analysis by screening calorimetry technique. Chemical Engineering Transactions 2012, 26, 27.

(8) Maschio, G.; Lister, D. G.; Casson Moreno, V. Use of screening analysis calorimetry in the study of peroxides decomposition. Chemical Engineering Transactions 2012, 19, 347.

(9) Steensma, M.; Westerterp, K. R. Thermally safe operation of a semibatch reactor for liquid-liquid reactions. Slow reactions. Ind. Eng. Chem. Res. 1990, 29, 1259.

(10) Westerterp, K. R.; Molga, E. J. No more runaways in fine chemical reactors. Ind. Eng. Chem. Res. 2004, 43, 4585.

(11) Maestri, F.; Rota, R. Temperature diagrams for preventing decomposition or side reactions in liquid-liquid semibatch reactors. Chem. Eng. Sci. 2006, 61, 3068.

(12) Molga, E. J.; Lewak, M; Westerterp, K. R. Runaway prevention in liquid-phase homogeneous semibatch reactors. Chem. Eng. Sci. 2007, 62, 5074. 
(13) Maestri, F.; Rota, R. Safe and productive operation of homogeneous semibatch reactors involving autocatalytic reactions with arbitrary reaction order. Ind. Eng. Chem. Res. 2007, 46, 5333. (14) Maestri, F.; Copelli, S.; Rota, R.; Lunghi, A.; Gigante, L.; Cardillo, P. Simple procedure for optimal scale-up of fine chemical processes. I: practical tools. Ind. Eng. Chem. Res. 2009, 48 (3), 1307.

(15) Copelli, S.; Derudi, M.; Maestri, F.; Rota, R. Safe operating conditions for semibatch processes involving consecutive reactions with autocatalytic behavior. Chem. Eng. Sci. 2010, 65 (20), 5464.

(16) Copelli, S.; Derudi, M.; Rota, R. Topological criteria to safely optimize hazardous chemical processes involving consecutive reactions. Ind. Eng. Chem. Res. 2010, 49, 4583.

(17) Copelli, S.; Derudi, M.; Rota, R.; Lunghi, A.; Pasturenzi, C. Experimental design of topological curves to safely optimize highly exothermic complex reacting systems. Ind. Eng. Chem. Res. 2011, 50 (17), 9910.

(18) Eigenberger, G.; Schuler, H. Reaktorstabilität und Sichere Reaktionsführung. Chem. Ing. Tech. 1986, 58, 655.

(19) Maestri, F.; Rota, R. Kinetic-free safe operation of fine chemical runaway reactions: a general criterion. Ind. Eng. Chem. Res. 2016, 55, 925.

(20) Maestri, F.; Rota, R. Kinetic-Free Safe Optimization of a Semibatch Runaway Reaction: Nitration of 4-Chloro Benzotrifluoride. Ind. Eng. Chem. Res. 2016, 55, 12786.

(21) Maestri, F.; Rota, R. Simple Monitoring of Semibatch Polymerization Processes: An Integrated Criterion. Ind. Eng. Chem. Res. 2017, 56, 7434.

(22) Hugo, P.; Steinbach, J.; Stoessel, F. Calculation of the Maximum Temperature in Stirred Tank Reactors in case of a Breakdown of Cooling. Chem. Eng. Sci. 1988, 43, 2147.

(23) Copelli, S.; Derudi, M.; Cattaneo, C. S.; Nano, G., Raboni, M.; Torretta, V.; Rota, R. Synthesis of 4-Chloro-3-nitrobenzotrifluoride: Industrial thermal runaway simulation due to cooling system failure. Process. Saf. Environ. 2014, 92, 659.

(24) Koufopanos, C. A.; Karetsou, A.; Papayannakos, N. G. Dynamic Response and Safety 22 
Assessment of a Batch Process on Cooling Breakdown. Chem. Eng. Technol. 1994, 17, 358.

(25) Serra, E; Nomen, R.; Sempere, J. Maximum Temperature Attainable by Runaway of Synthesis Reaction in Semibatch Processes. J. Loss Prev. Proc. Ind. 1997, 10, 211.

(26) Kidam, K; Hurme, M. Statistical Analysis of Contributors to Chemical Process Accidents. Chem.

Eng. Technol. 2013, 36, 167. 
$\underline{\text { Tables }}$

\begin{tabular}{|c|c|c|}
\hline & Continuous aqueous phase & Dispersed organic phase \\
\hline Density & $1360 \mathrm{~kg} / \mathrm{m}^{3}$ & $817 \mathrm{~kg} / \mathrm{m}^{3}$ \\
\hline Heat capacity & $2660 \mathrm{~J} /(\mathrm{kg} \cdot \mathrm{K})$ & $2523 \mathrm{~J} /(\mathrm{kg} \cdot \mathrm{K})$ \\
\hline
\end{tabular}

Table 1. Nitric acid oxidation of 2-octanol: physical properties of the liquid phases.

\begin{tabular}{|c|ll|c|ll|}
\hline \multicolumn{3}{|c|}{ 2-octanol oxidation to 2-octanone } & \multicolumn{3}{c|}{ 2-octanone oxidation to carboxylic acids } \\
\hline $\mathrm{m}_{\mathrm{A}} \cdot \mathrm{k}_{\infty, \text { nol }}$ & $10^{5}$ & $\mathrm{~m}^{3} /(\mathrm{kmol} \cdot \mathrm{s})$ & $\mathrm{m}_{\mathrm{P}} \cdot \mathrm{k}_{\infty, \text { none }}$ & $10^{10}$ & $\mathrm{~m}^{3} /(\mathrm{kmol} \cdot \mathrm{s})$ \\
\hline $\mathrm{E}_{\mathrm{nol}} / \mathrm{R}$ & 11300 & $\mathrm{~K}$ & $\mathrm{E}_{\text {none }} / \mathrm{R}$ & 12000 & $\mathrm{~K}$ \\
\hline $\mathrm{m}_{\mathrm{H}_{0}, \text { nol }}$ & 6.6 & - & $\mathrm{m}_{\mathrm{H}_{0}, \text { none }}$ & 2.2 & - \\
\hline$\Delta \widetilde{\mathrm{H}}_{\mathrm{nol}}$ & $-1.6 \cdot 10^{8}$ & $\mathrm{~J} / \mathrm{kmol}$ & $\Delta \widetilde{\mathrm{H}}_{\text {none }}$ & $-5.2 \cdot 10^{8}$ & $\mathrm{~J} / \mathrm{kmol}$ \\
\hline
\end{tabular}

Table 2. Nitric acid oxidation of 2-octanol: thermodynamic and kinetic parameters of the main reaction (nol) and of the consecutive reaction (none).

\begin{tabular}{|ll|ll|}
\hline $\mathrm{n}_{\mathrm{A} 1}$ & $3.8 \mathrm{kmol}$ & $\mathrm{V}_{\mathrm{dos}}$ & $0.6 \mathrm{~m}^{3}$ \\
\hline $\mathrm{n}_{\mathrm{N} 0}$ & $19.43 \mathrm{kmol}$ & $\mathrm{V}_{\mathrm{r} 0}$ & $1.5 \mathrm{~m}^{3}$ \\
\hline$\xi_{\mathrm{B} 0}$ & 0.035 & $\left(\mathrm{U} \cdot \mathrm{A}_{\mathrm{H}}\right)_{0}$ & $1500 \mathrm{~W} / \mathrm{K}$ \\
\hline
\end{tabular}

Table 3. Nitric acid oxidation of 2-octanol: operating parameters of the SBR. 


\section{Captions to the figures}

Figure 1. Exothermic SBR with consecutive degradation of a target product. Non-ignition operating conditions. Typical trends for: conversion and yield vs. time (A); reaction temperature vs. time (B); $\mathrm{X}$ number and coreactant conversion degree vs. time $(\mathrm{C})$. Homogenous reaction system with: $v_{B}=v_{C}$; $\Phi=1, \mathrm{~S}=5000, \mathrm{~K}=1.5 ; \mathrm{Wt}=30, \mathrm{R}_{\mathrm{H}}=1 ;\left(v_{\mathrm{A}} \mathrm{Da} \mathrm{RE}\right)_{1}=0.618, \varepsilon=0.35, \gamma_{1}=35, \Delta \widetilde{\mathrm{T}}_{\mathrm{ad}, 0 \mathrm{C}}=0.43 ; \widetilde{\mathrm{T}}_{0}=\widetilde{\mathrm{T}}_{\mathrm{dos}}=$ $\widetilde{\mathrm{T}}_{\text {cool }}=1$. Dimensionless parameters referred to $\mathrm{T}_{\mathrm{R}}=300 \mathrm{~K}$.

Figure 2. Exothermic SBR with consecutive degradation of a target product. Ignited and selective operating conditions. Typical trends for: conversion and yield vs. time (A); reaction temperature vs. time (B); X number and coreactant conversion degree vs. time (C). Parameters as in Figure 1 with $\widetilde{\mathrm{T}}_{0}=\widetilde{\mathrm{T}}_{\mathrm{dos}}=\widetilde{\mathrm{T}}_{\text {cool }}=1.1$.

Figure 3. Exothermic SBR with consecutive degradation of a target product. Ignited and marginally unselective operating conditions. Typical trends for: conversion and yield vs. time (A); reaction temperature vs. time (B); X number and coreactant conversion degree vs. time (C). Parameters as in Figure 1 with $\widetilde{\mathrm{T}}_{0}=\widetilde{\mathrm{T}}_{\text {dos }}=\widetilde{\mathrm{T}}_{\text {cool }}=1.15$.

Figure 4. Exothermic SBR with consecutive degradation of a target product. Ignited and fully unselective operating conditions. Typical trends for: conversion and yield vs. time (A); reaction temperature vs. time (B); $\mathrm{X}$ number and coreactant conversion degree vs. time (C). Parameters as in Figure 1 with $\widetilde{\mathrm{T}}_{0}=\widetilde{\mathrm{T}}_{\text {dos }}=\widetilde{\mathrm{T}}_{\text {cool }}=1.25$.

Figure 5. Exothermic SBR with consecutive degradation of a target product. Typical trends of the reaction temperature at increasing $\Phi$ values. Parameters as in Figure 1 with $\widetilde{\mathrm{T}}_{0}=\widetilde{\mathrm{T}}_{\text {dos }}=\widetilde{\mathrm{T}}_{\text {cool }}=1.15$ and $\Phi=1,2,4$.

Figure 6. Exothermic SBR for the nitric acid oxidation of 2-octanol. Ignited and fully selective reactor regime with $t_{d o s}=10 \mathrm{~h}$ and $\mathrm{T}_{0}=-15^{\circ} \mathrm{C}$. Typical trends for: yields to 2-octanone and carboxylic acids vs. time (A); reaction temperature vs. time (B); X number and coreactant conversion degree vs. time (C).

Figure 7. Exothermic SBR for the nitric acid oxidation of 2-octanol. Uncontrolled reaction transition with $\mathrm{t}_{\mathrm{dos}}=10 \mathrm{~h}$ and $\mathrm{T}_{0}=0^{\circ} \mathrm{C}$. Typical trends for: yields to 2-octanone and carboxylic acids vs. time (A); reaction temperature vs. time (B); X number and coreactant conversion degree vs. time (C).

Figure 8. Exothermic SBR for the nitric acid oxidation of 2-octanol. Ignited and fully unselective reactor regime with $t_{\text {dos }}=10 \mathrm{~h}$ and $\mathrm{T}_{0}=10^{\circ} \mathrm{C}$. Typical trends for: yields to 2-octanone and carboxylic acids vs. time (A); reaction temperature vs. time (B); X number and coreactant conversion degree vs. time (C).

Figure 9. Exothermic SBR for the nitric acid oxidation of 2-octanol. Ignited and fully selective reactor regime with $t_{d o s}=20 \mathrm{~h}$ and $\mathrm{T}_{0}=-15^{\circ} \mathrm{C}$. Typical trends for: yields to 2-octanone and carboxylic acids vs. time (A); reaction temperature vs. time (B); X number and coreactant conversion degree vs. time (C).

Figure 10. Exothermic SBR for the nitric acid oxidation of 2-octanol. Gradual reaction transition with $\mathrm{t}_{\mathrm{dos}}=20 \mathrm{~h}$ and $\mathrm{T}_{0}=0^{\circ} \mathrm{C}$. Typical trends for: yields to 2-octanone and carboxylic acids vs. time (A); reaction temperature vs. time (B); X number and coreactant conversion degree vs. time (C).

Figure 11. Exothermic SBR for the nitric acid oxidation of 2-octanol. Ignited and fully unselective reactor regime with $\mathrm{t}_{\mathrm{dos}}=20 \mathrm{~h}$ and $\mathrm{T}_{0}=10^{\circ} \mathrm{C}$. Typical trends for: yields to 2-octanone and carboxylic acids vs. time (A); reaction temperature vs. time (B); X number and coreactant conversion degree vs. time (C). 


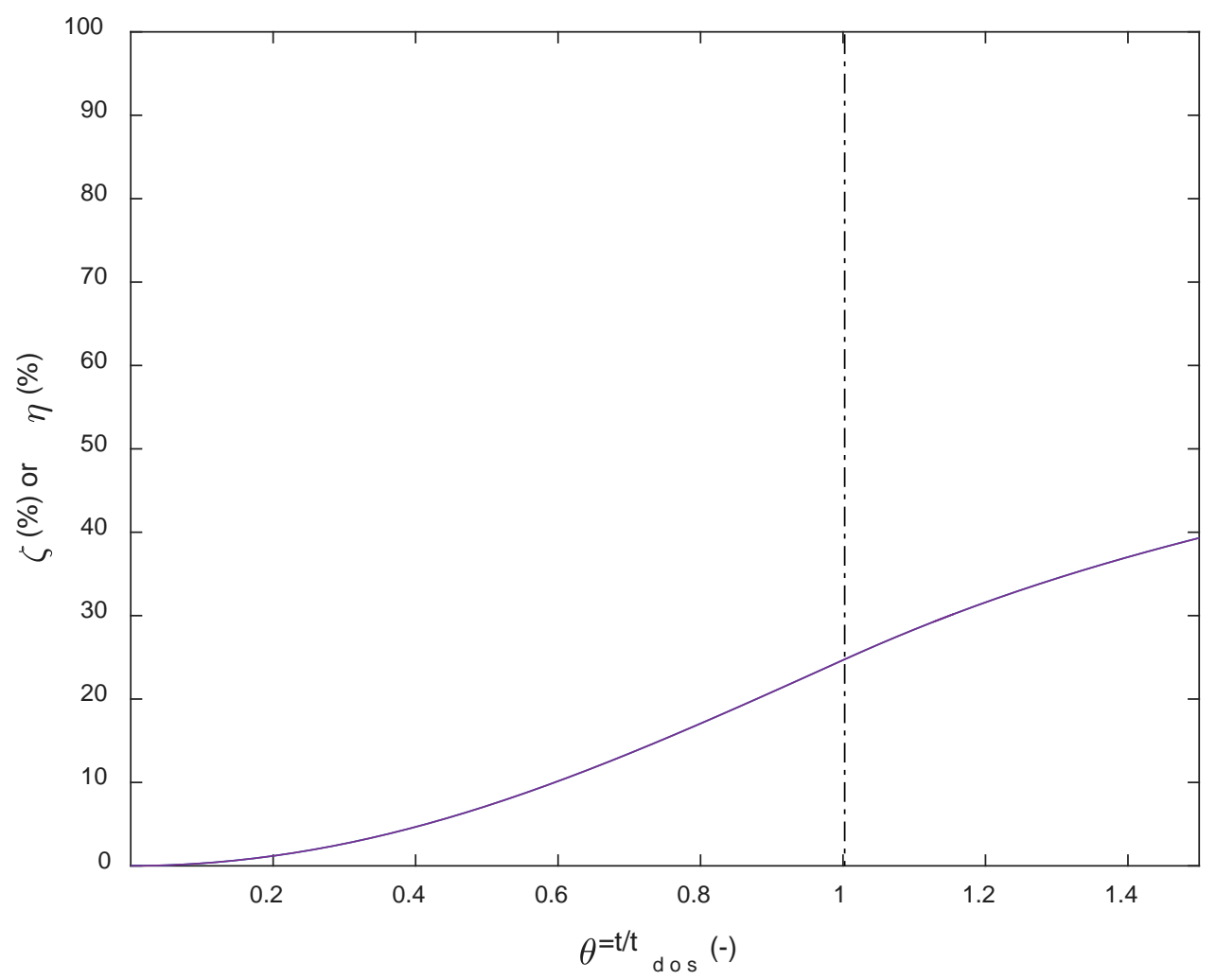

Fig. 1A

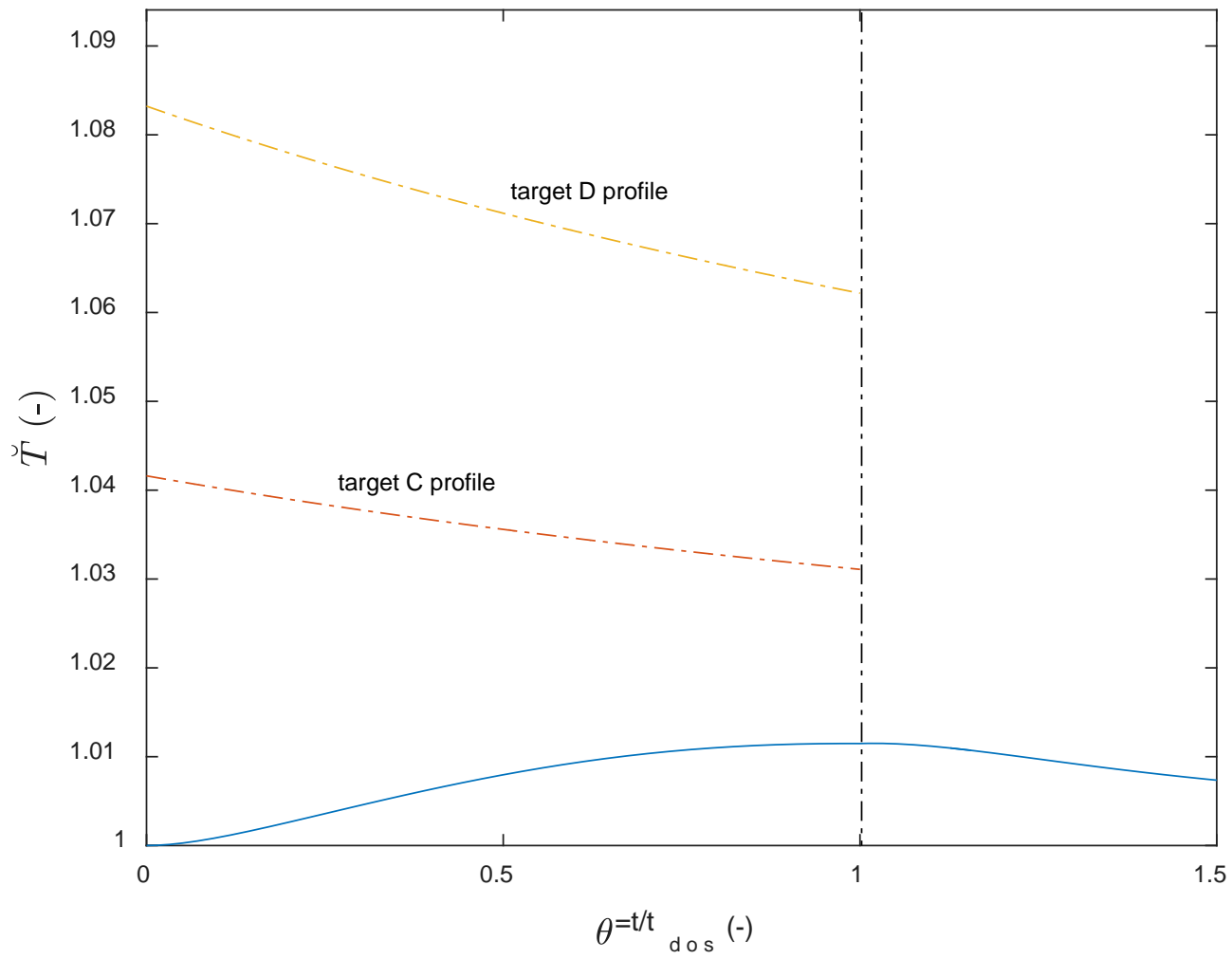

Fig. 1B 


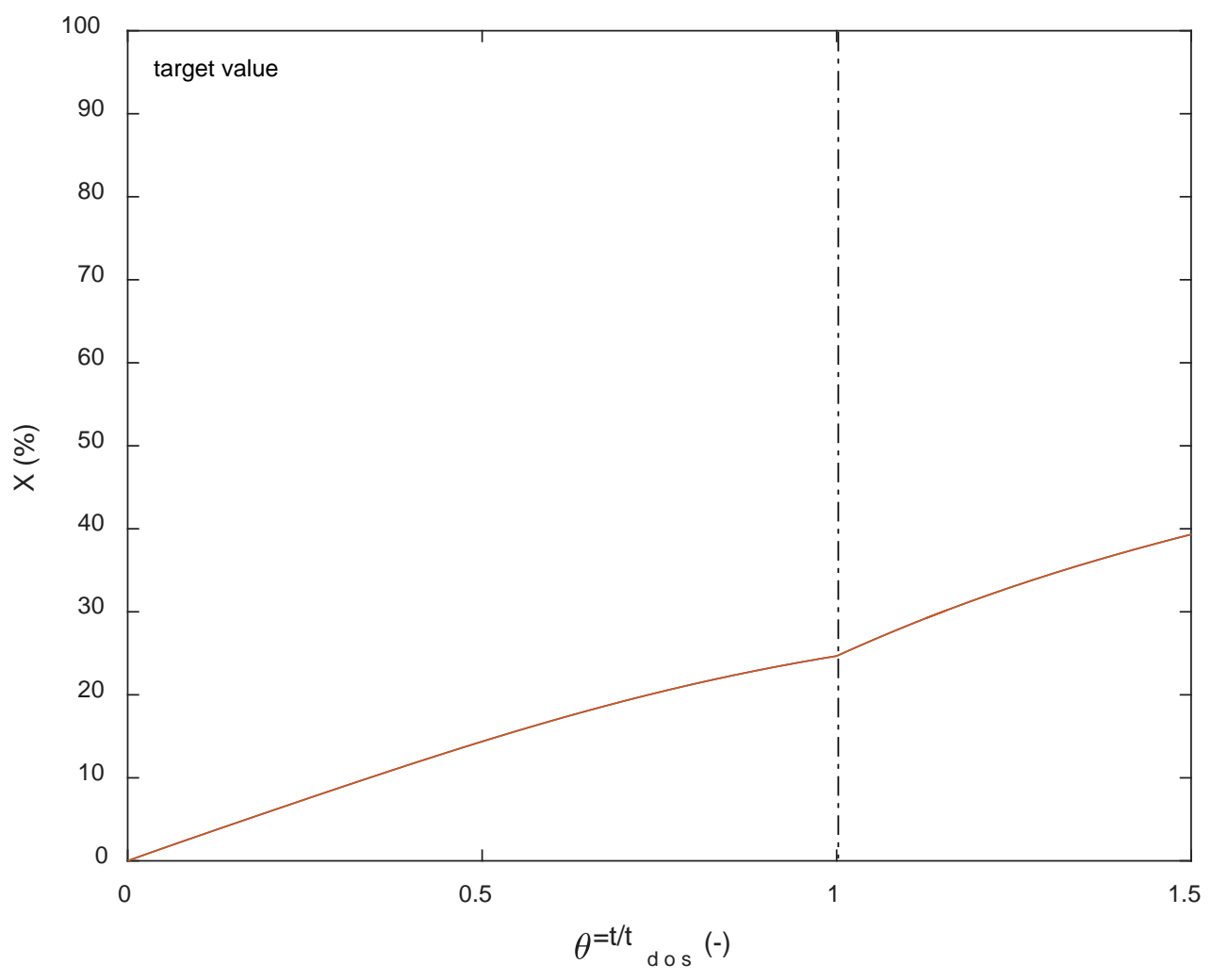

Fig. 1C 


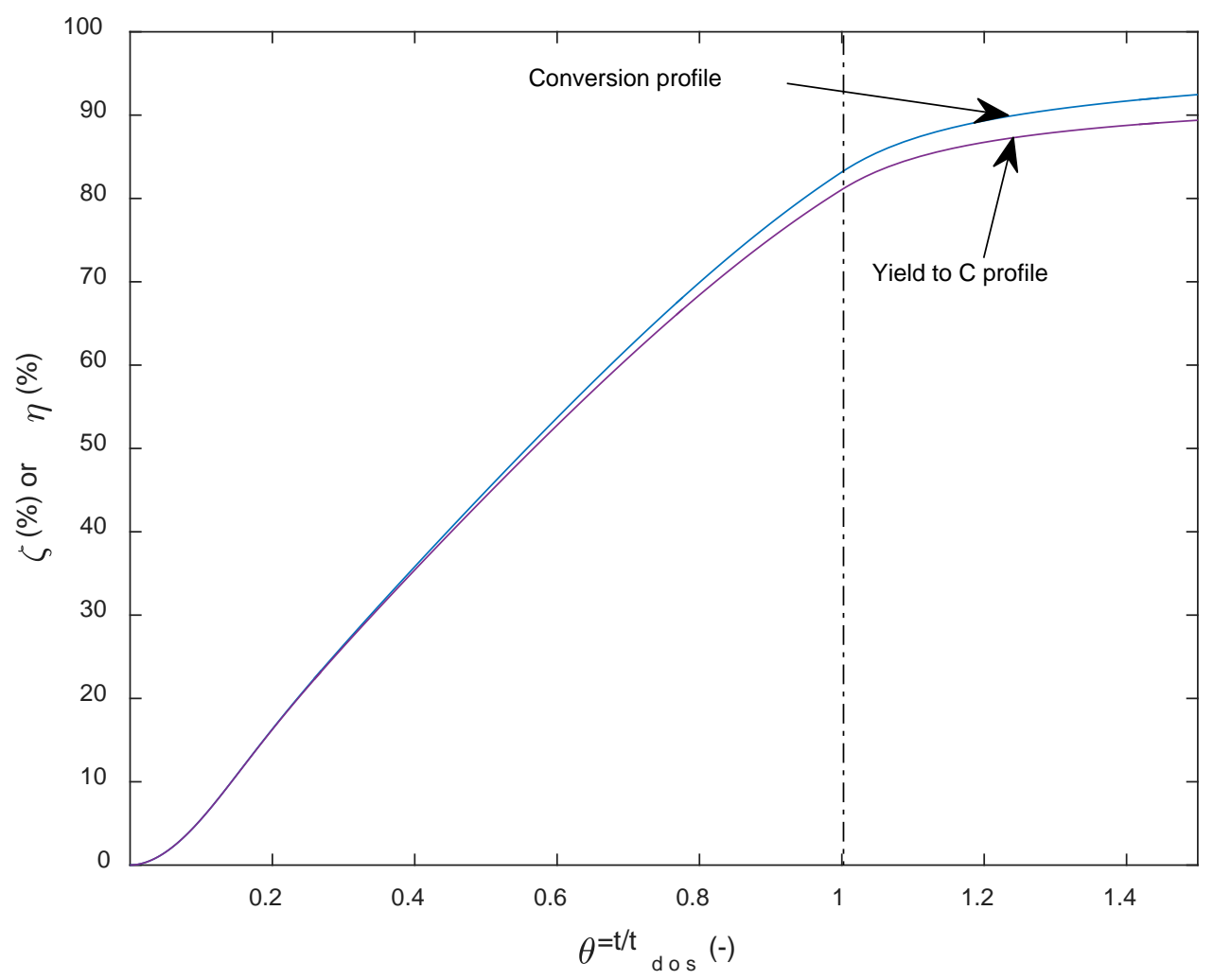

Fig. 2A

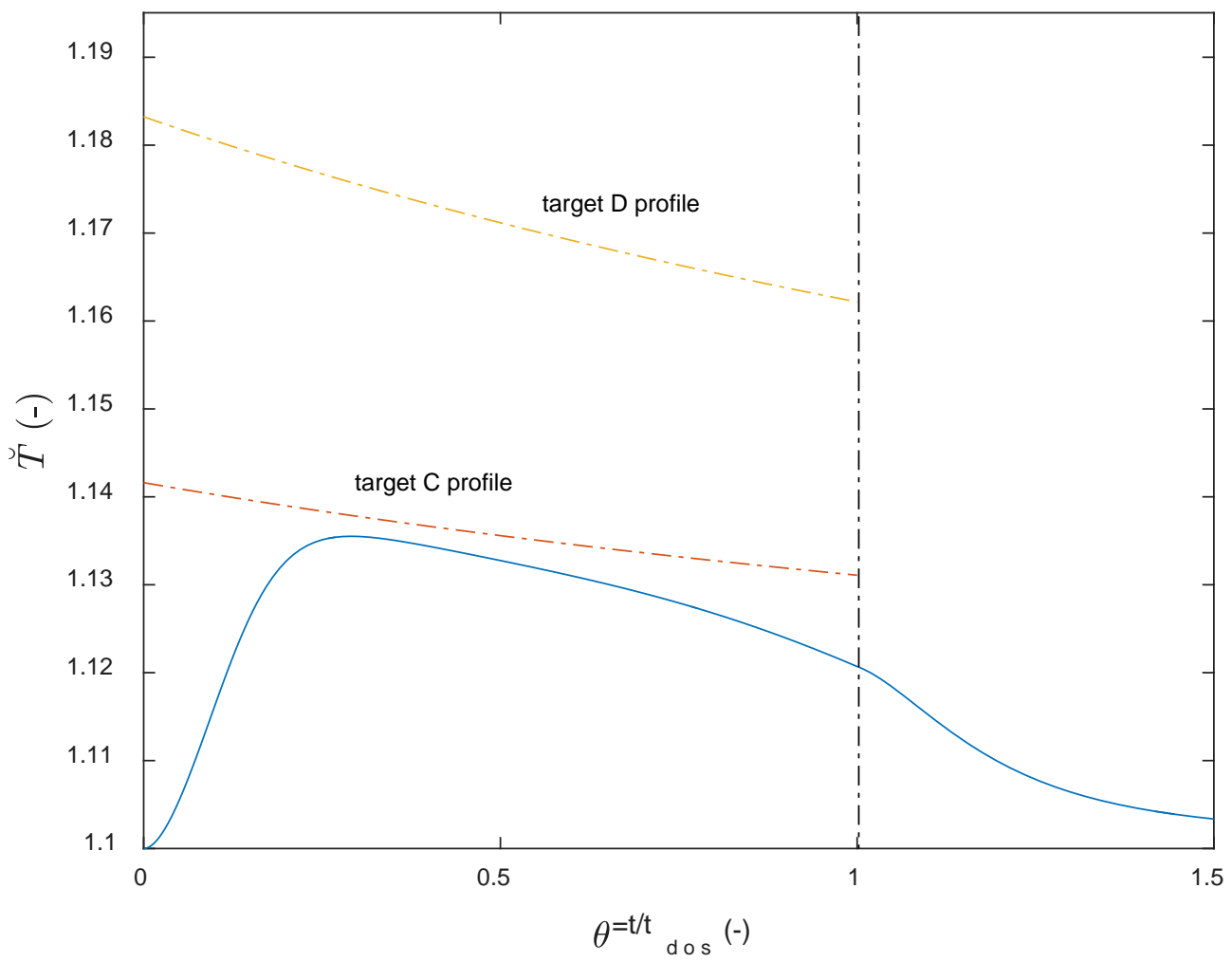

Fig. 2B 


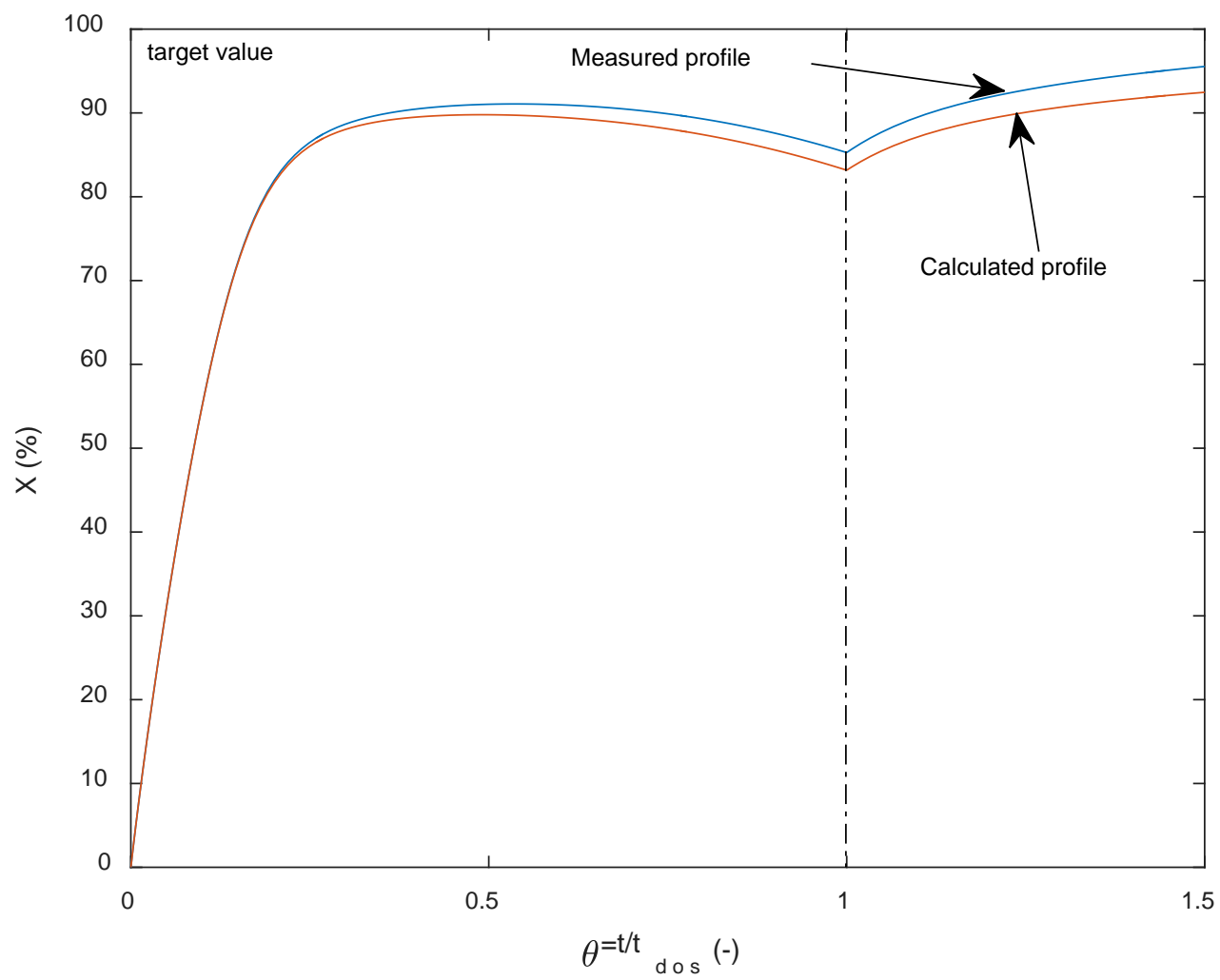

Fig. 2C 


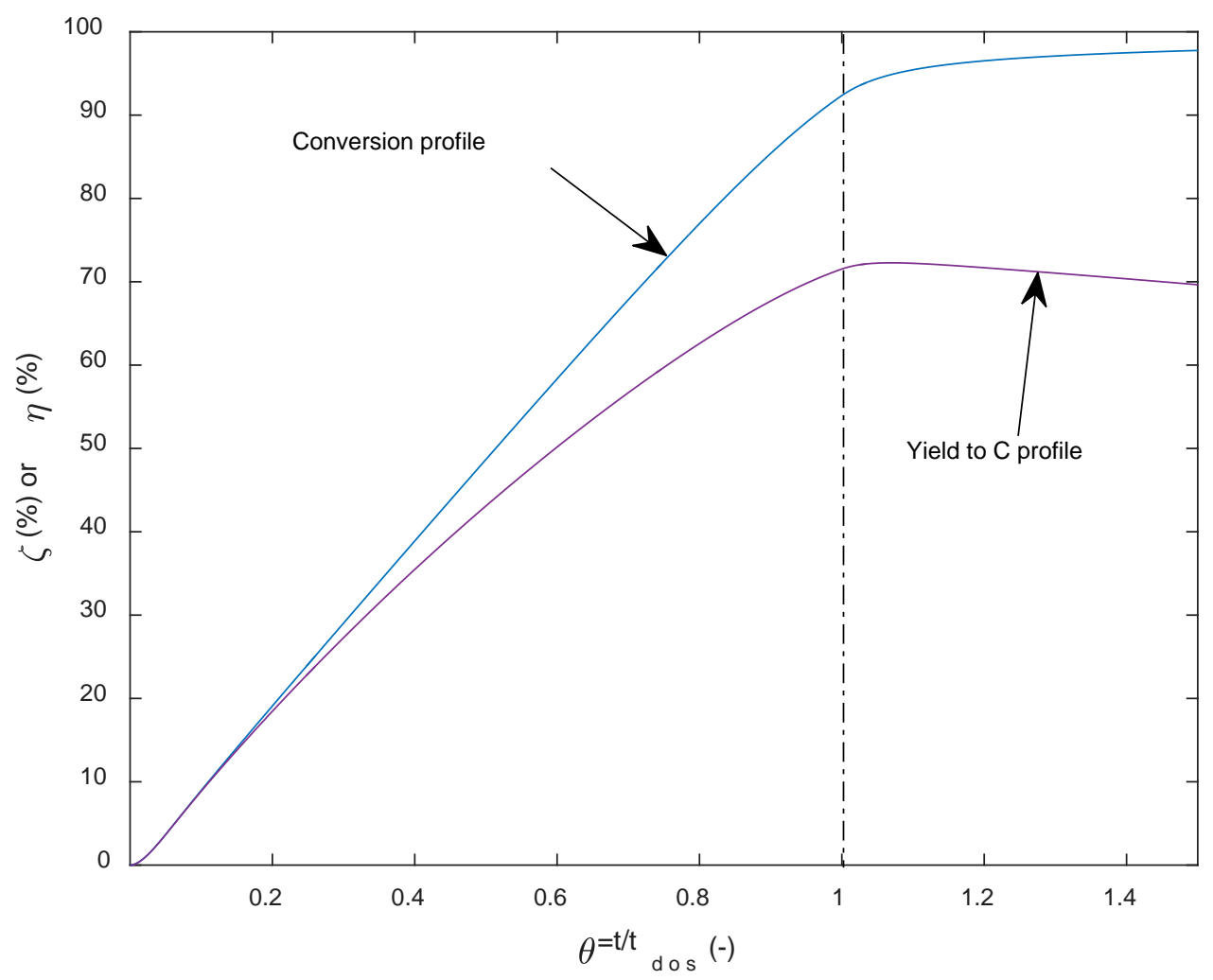

Fig. 3A

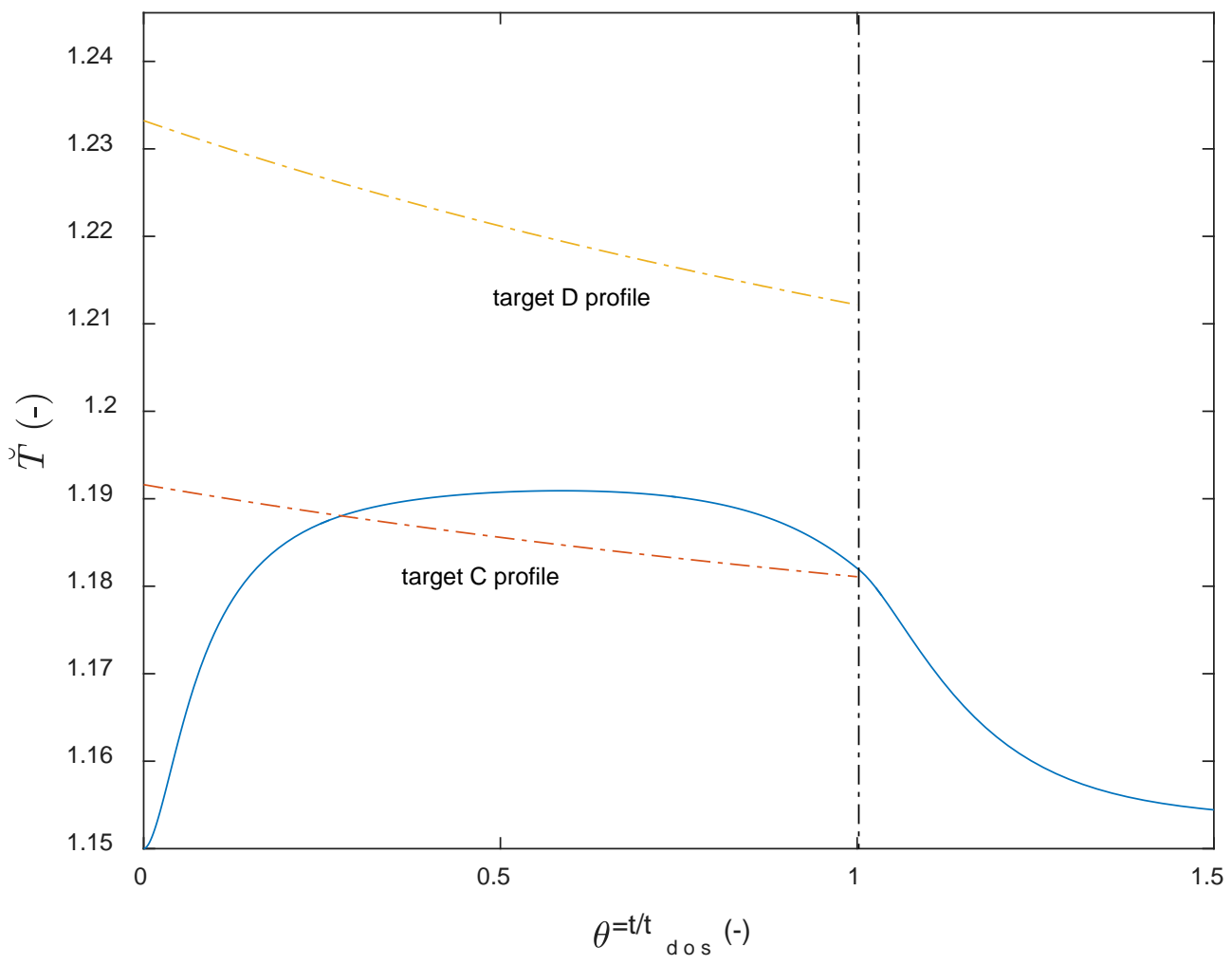

Fig. 3B 


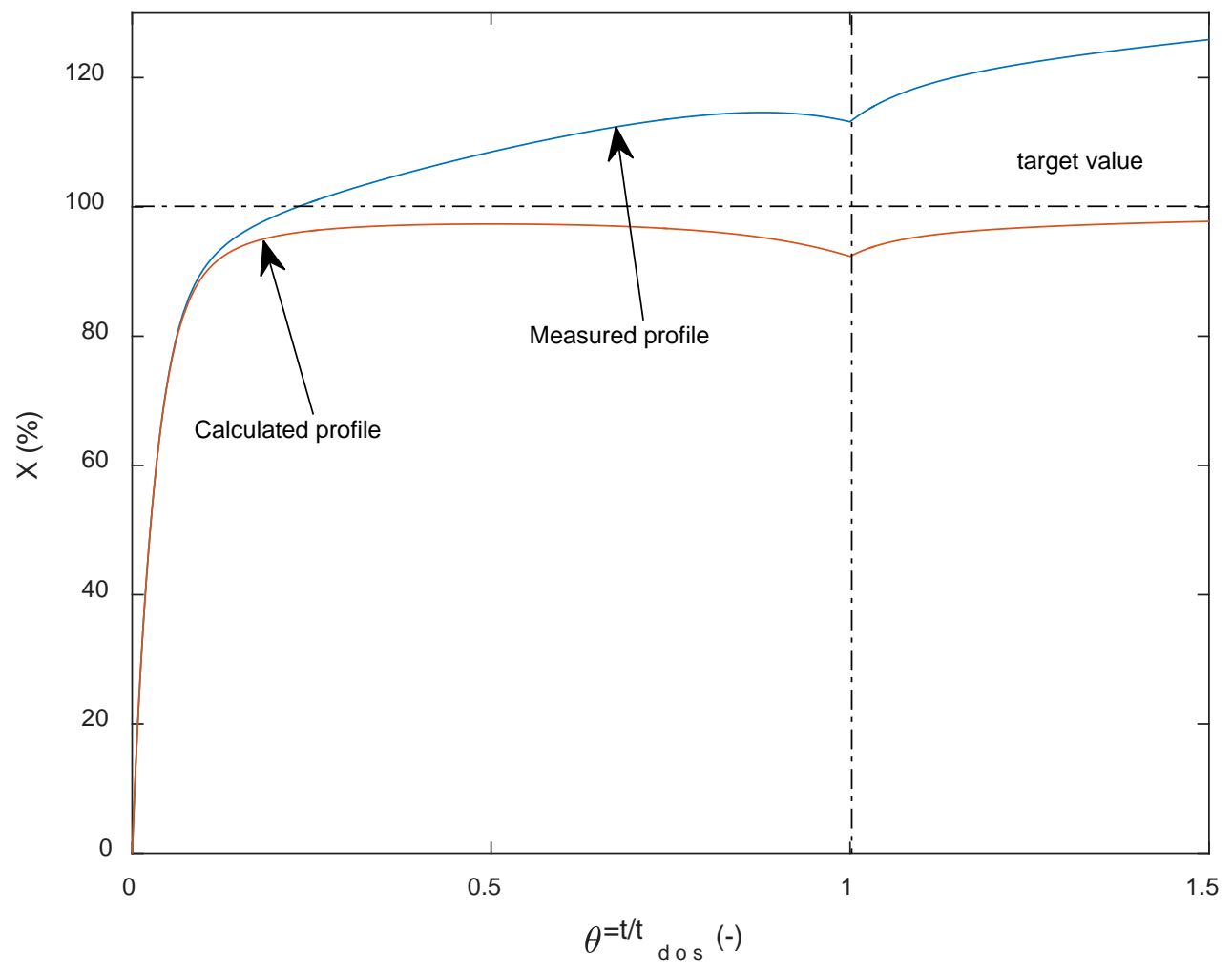

Fig. 3C 


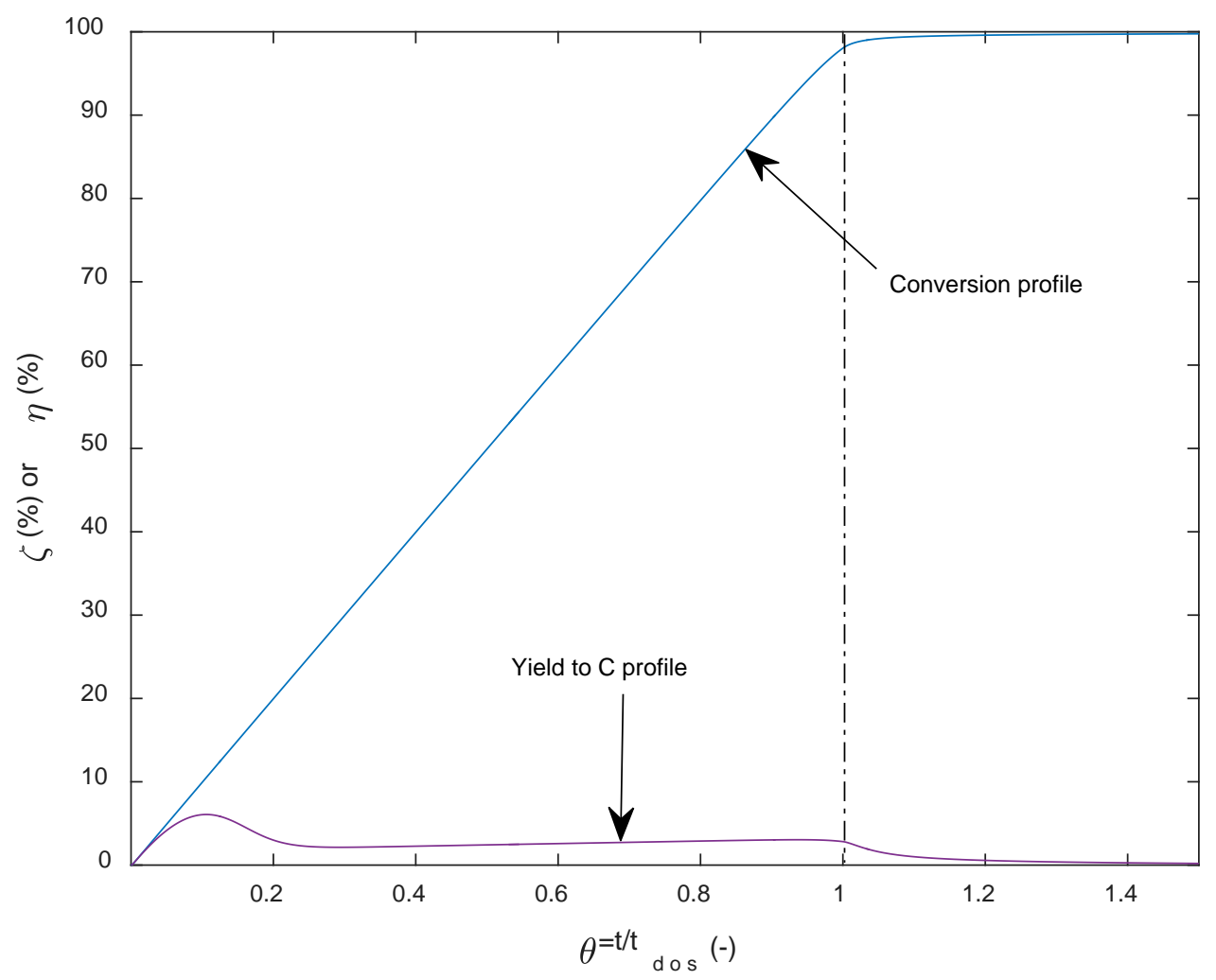

Fig. 4A

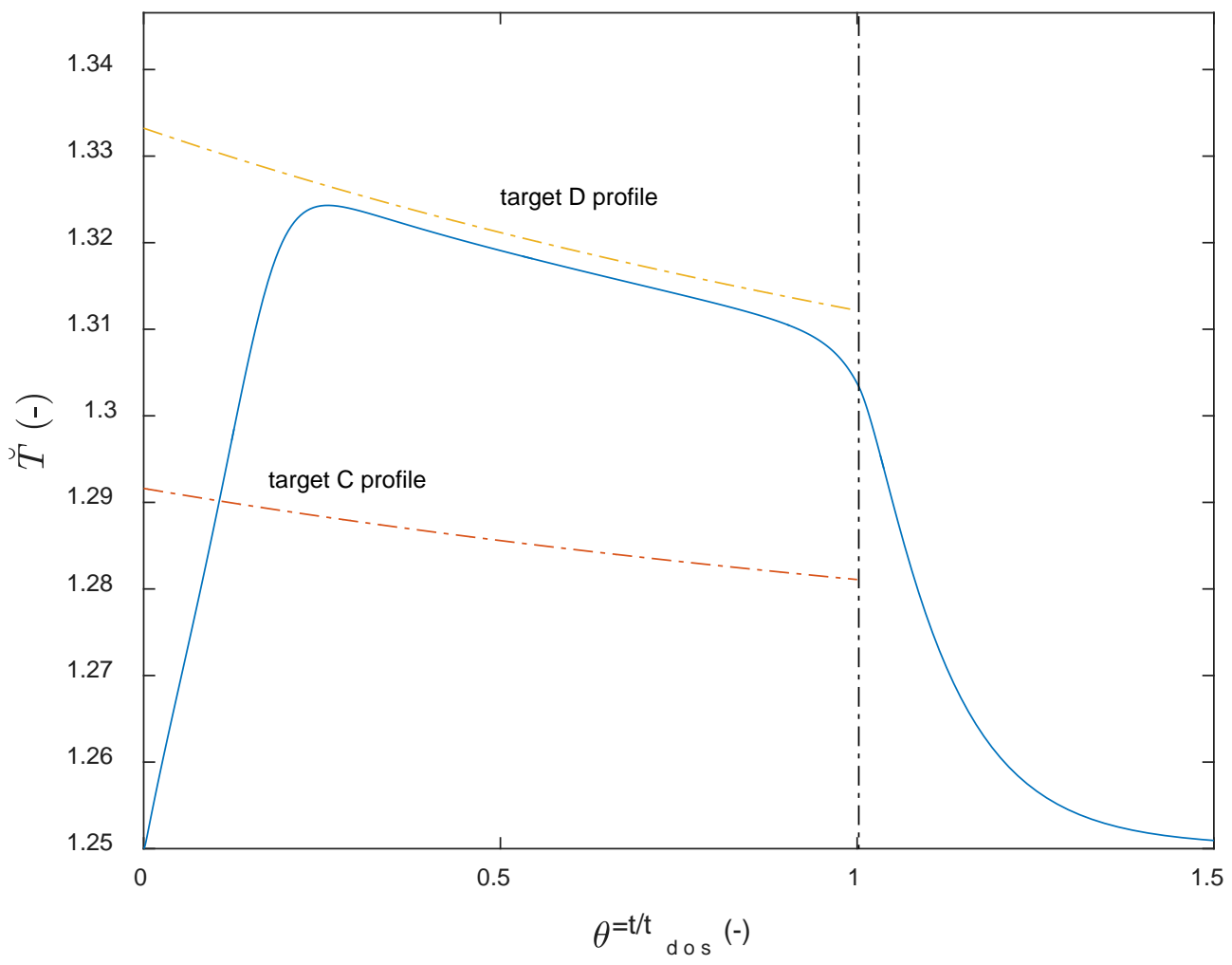

Fig. 4B 


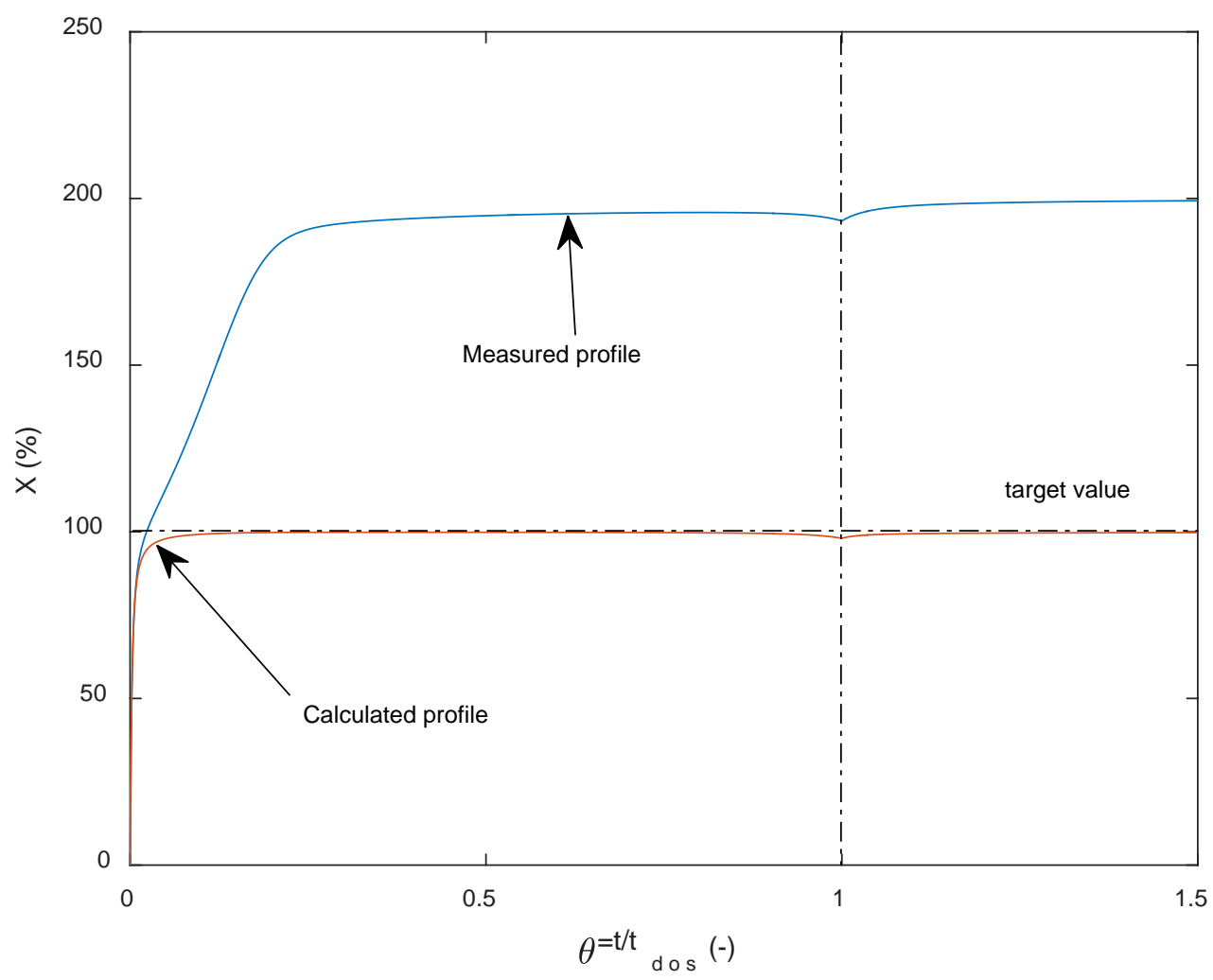

Fig. 4C 


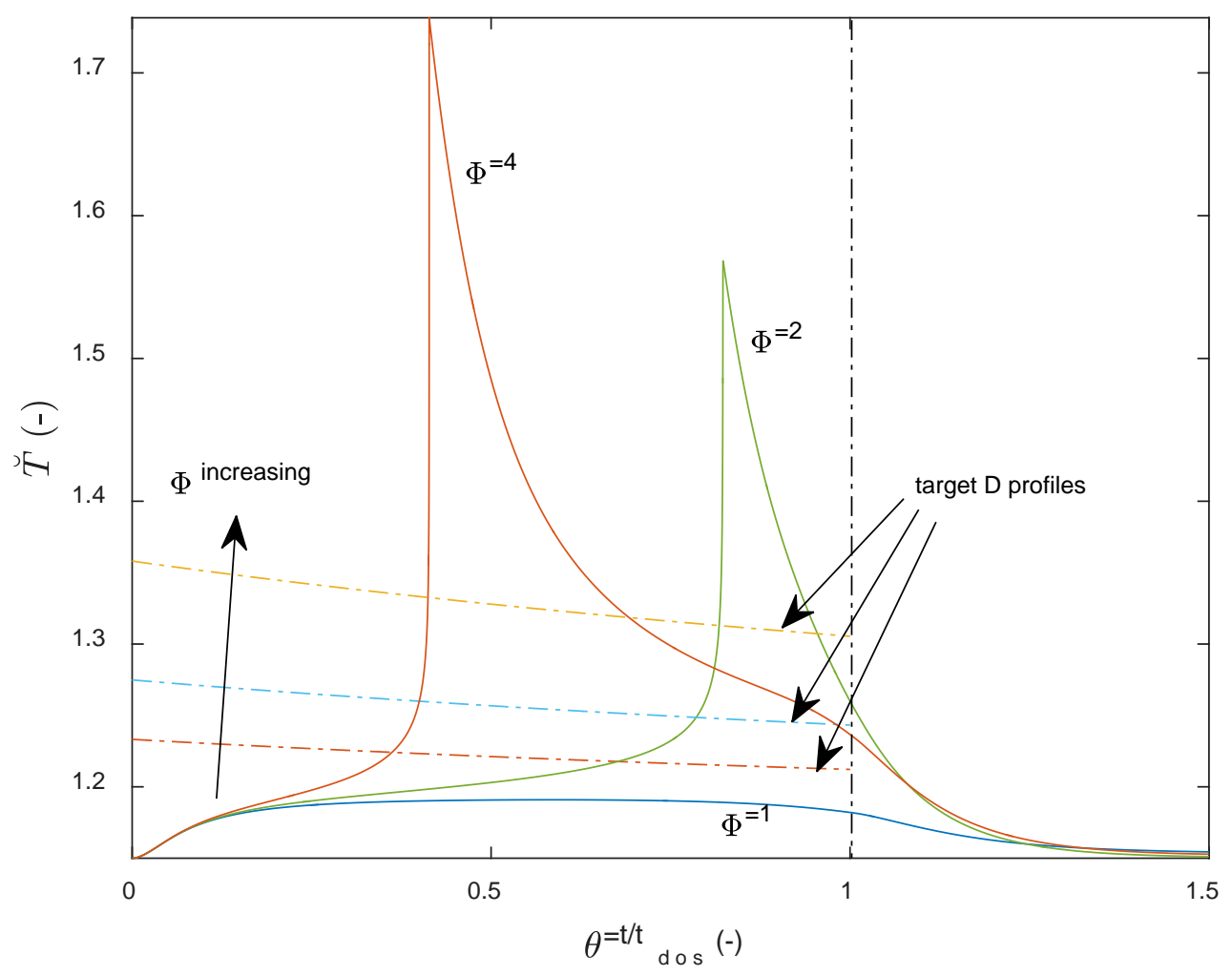

Fig. 5 


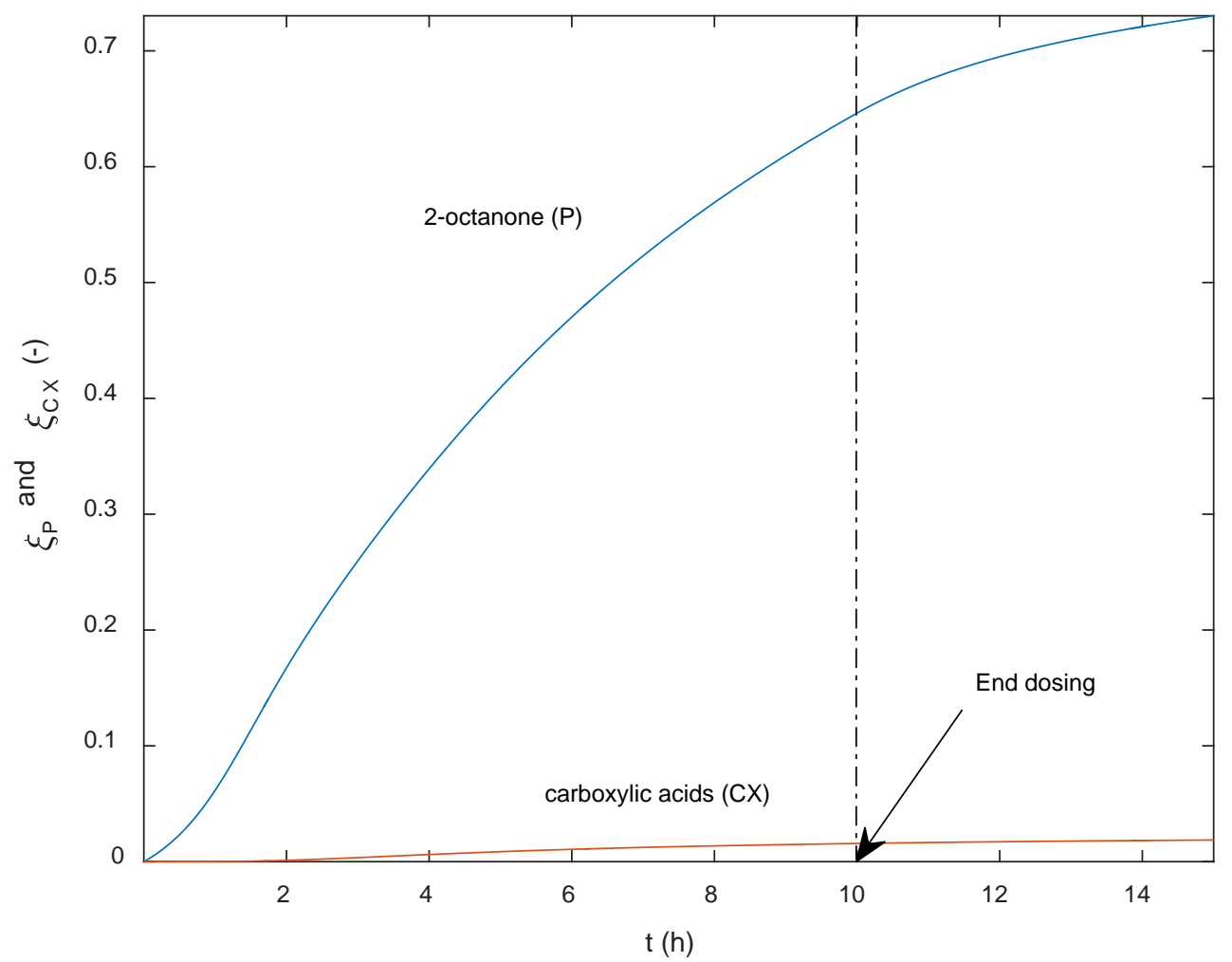

Fig. 6A

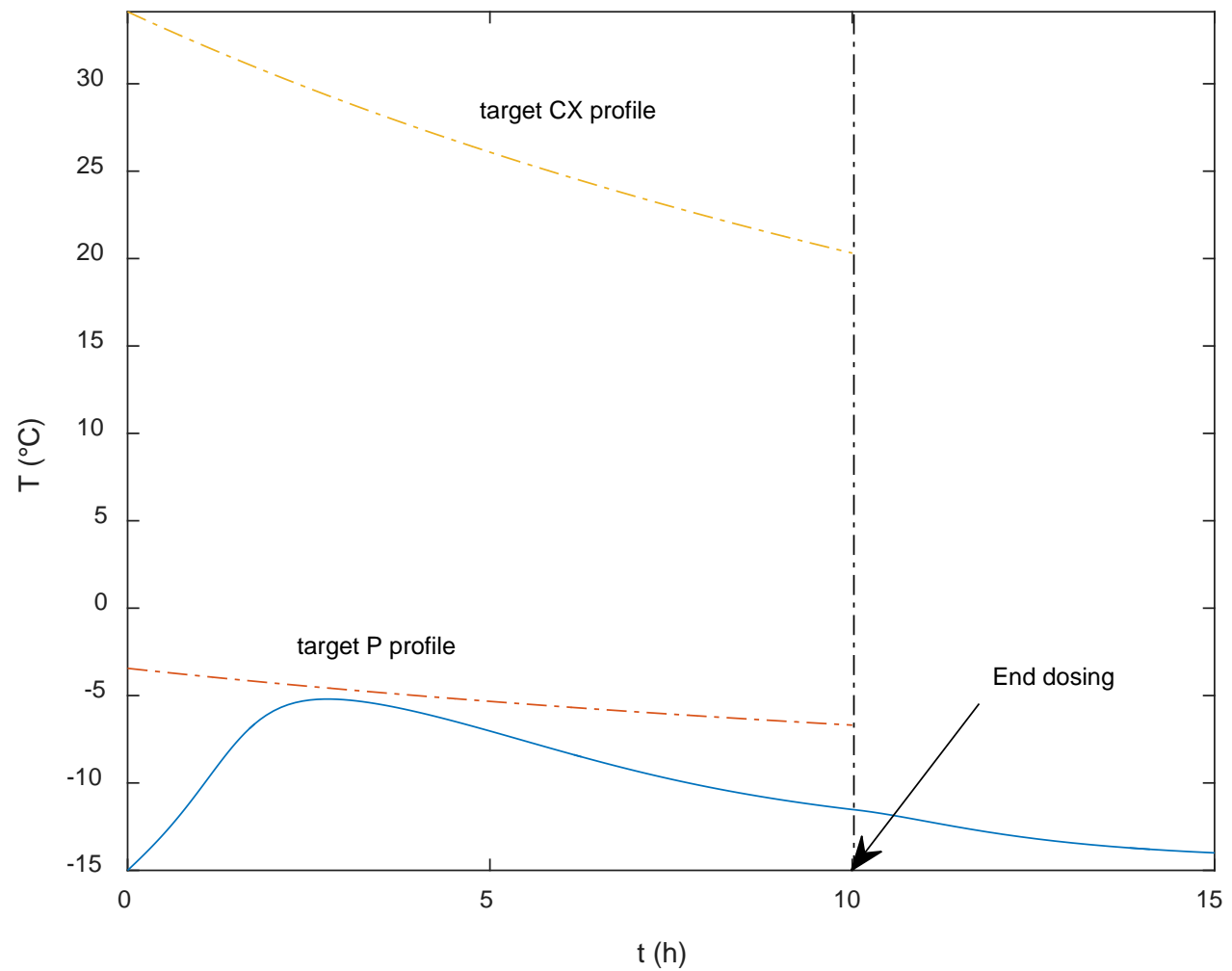

Fig. 6B 


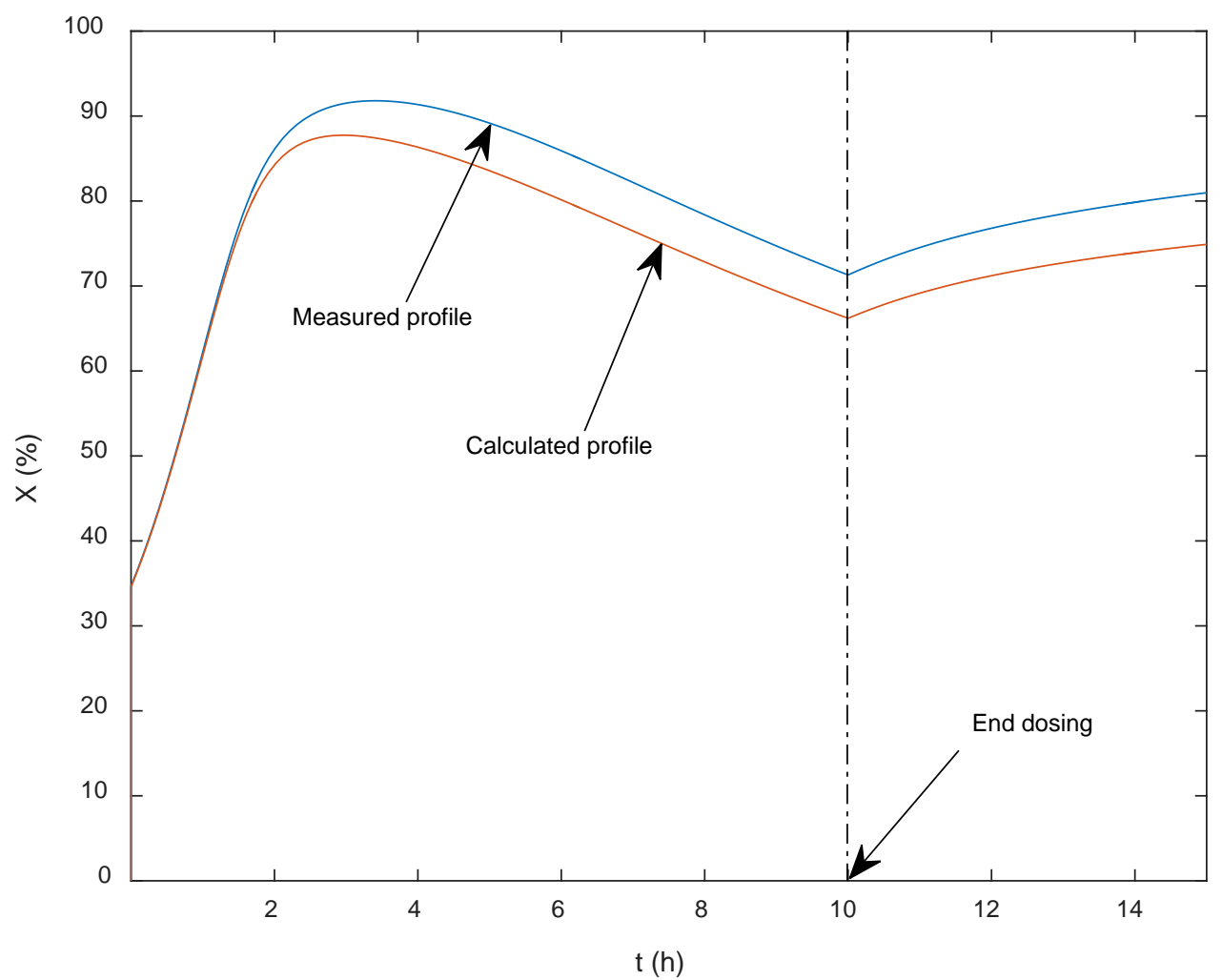

Fig. 6C 


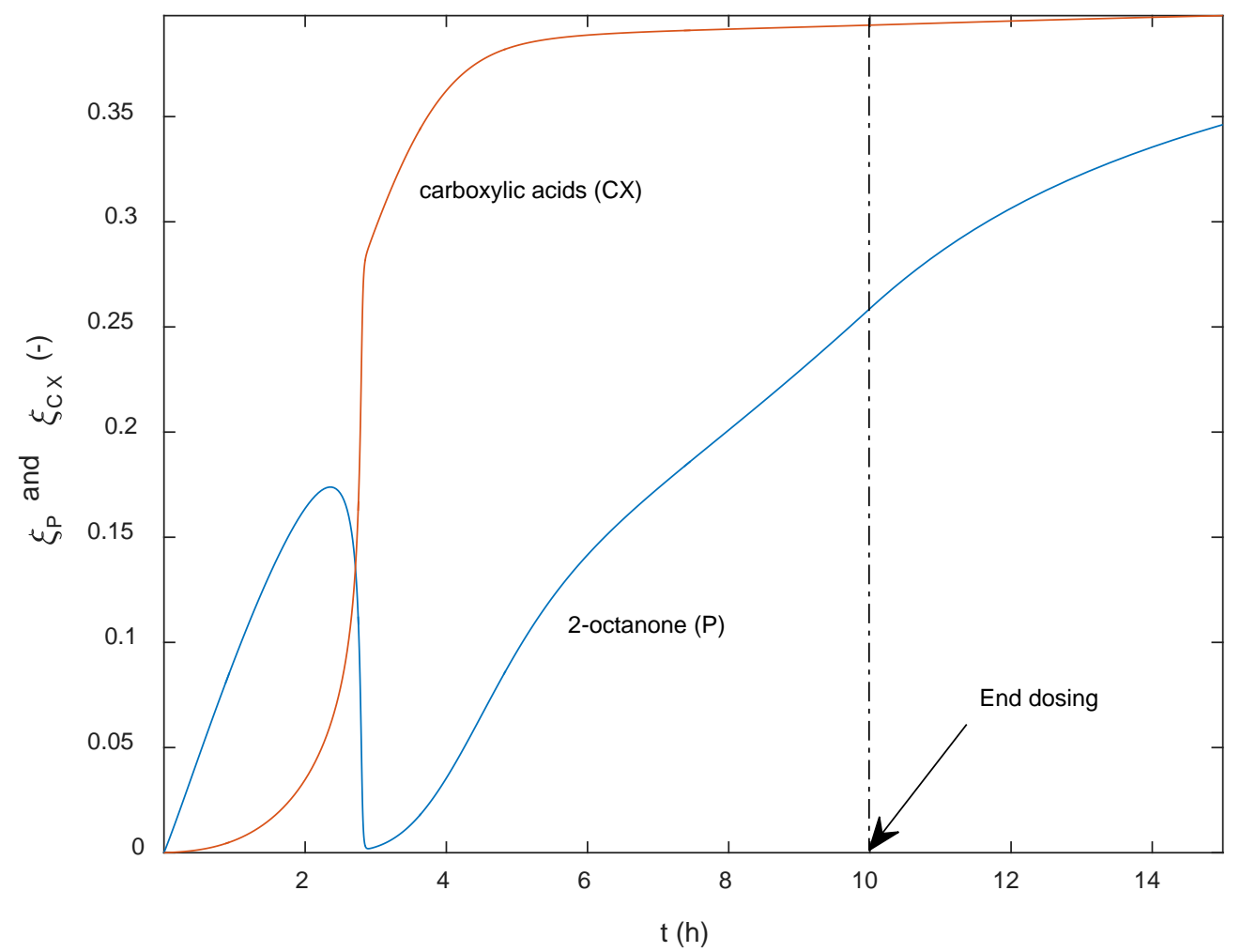

Fig. 7A

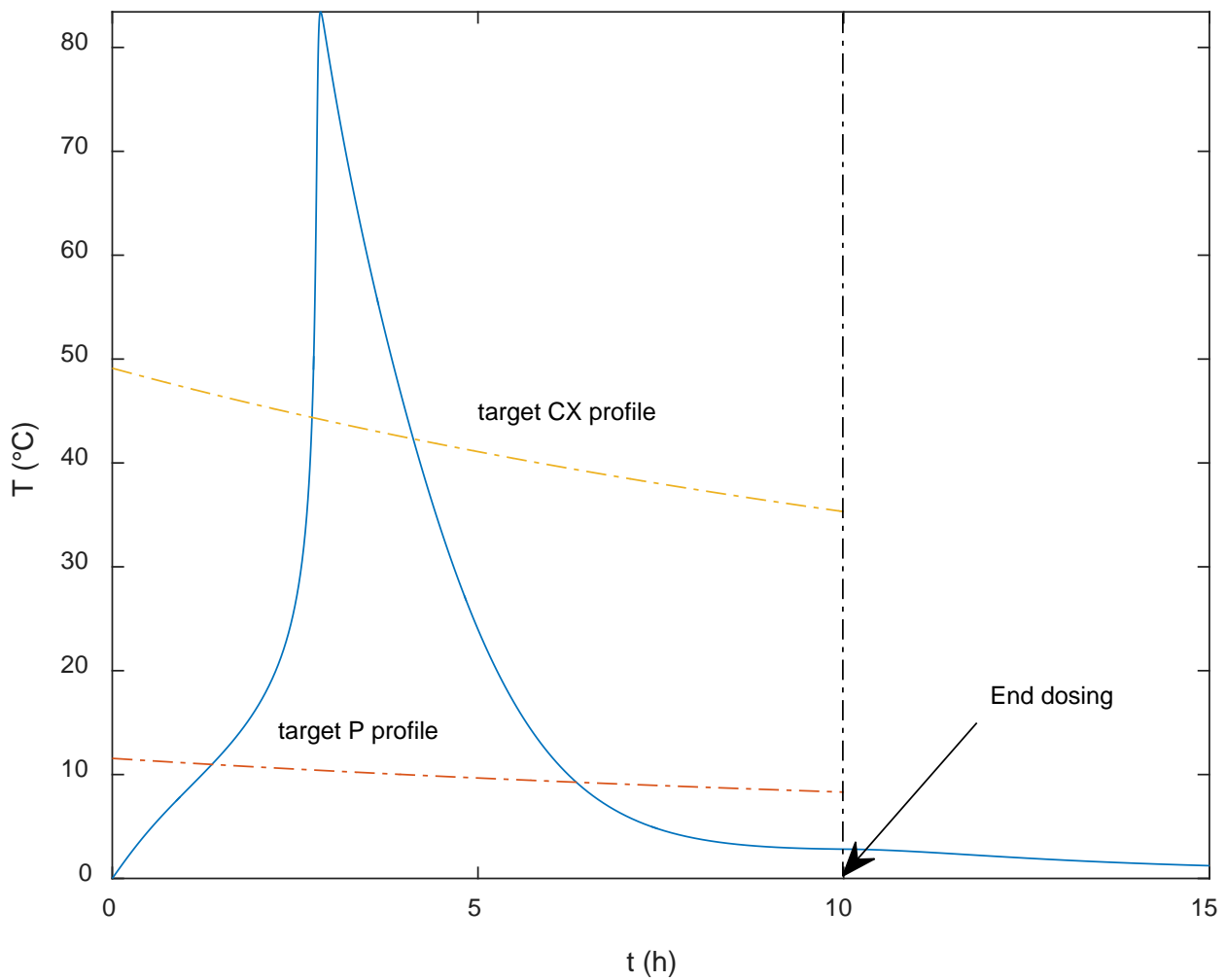

Fig. 7B 


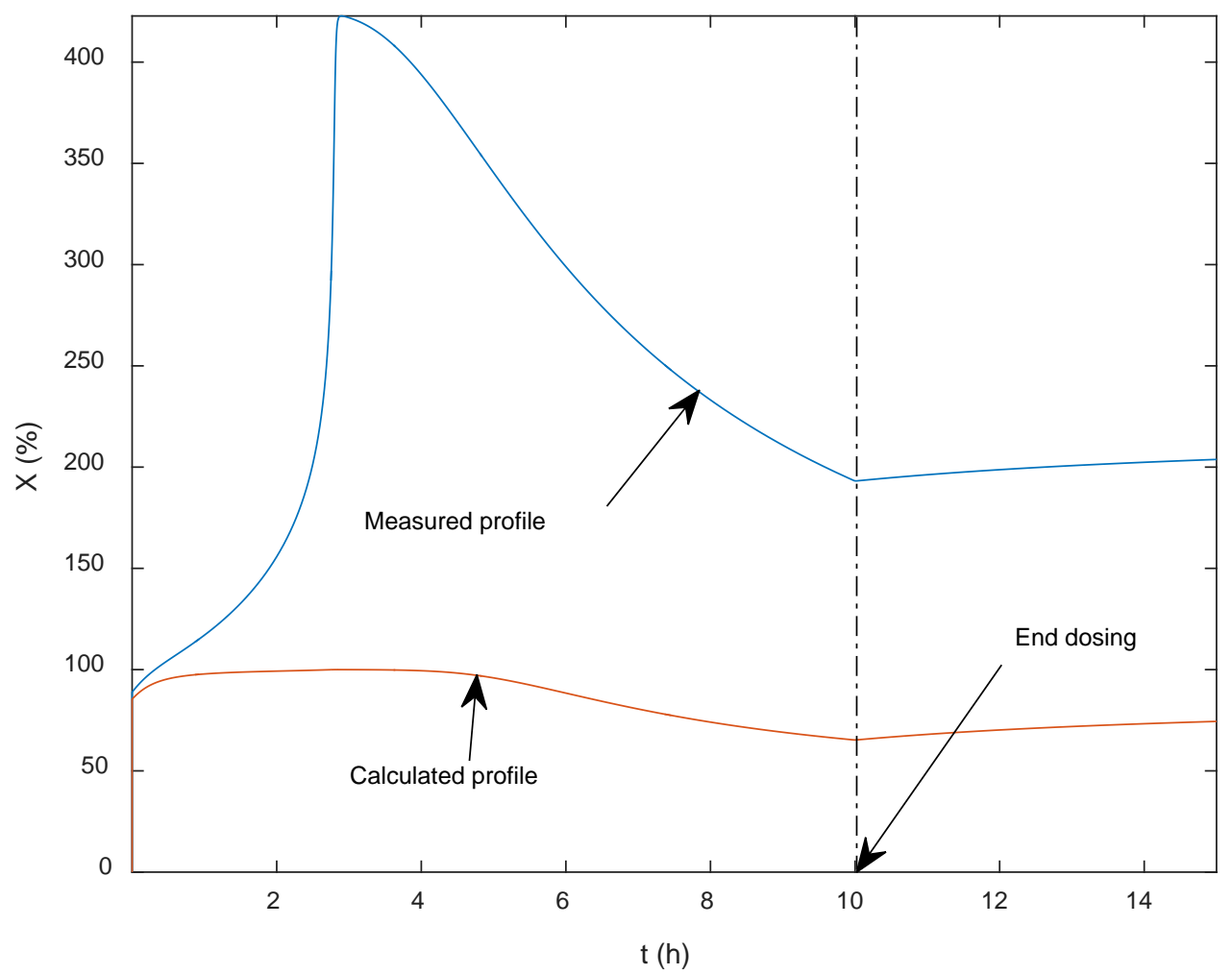

Fig. 7C 


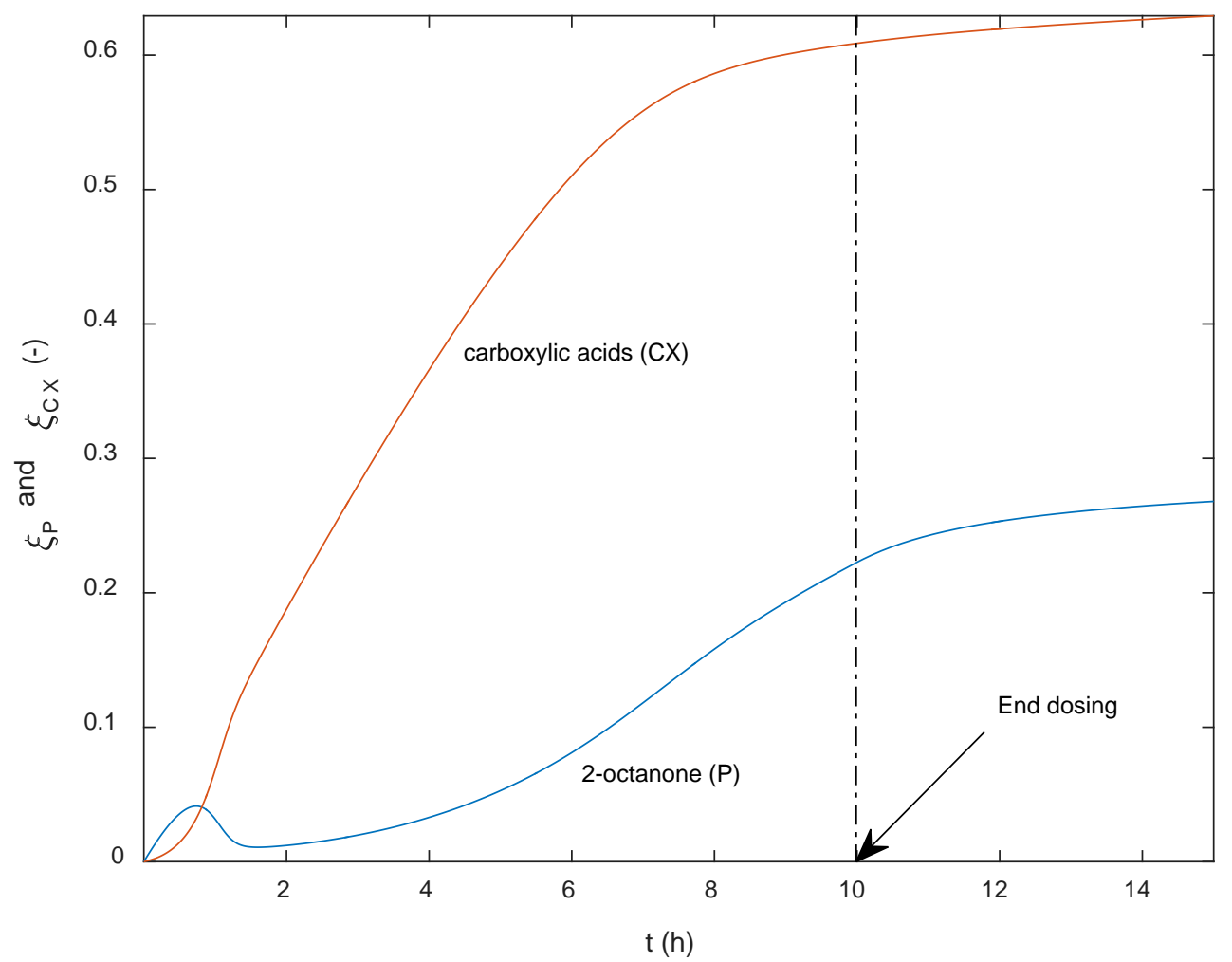

Fig. 8A

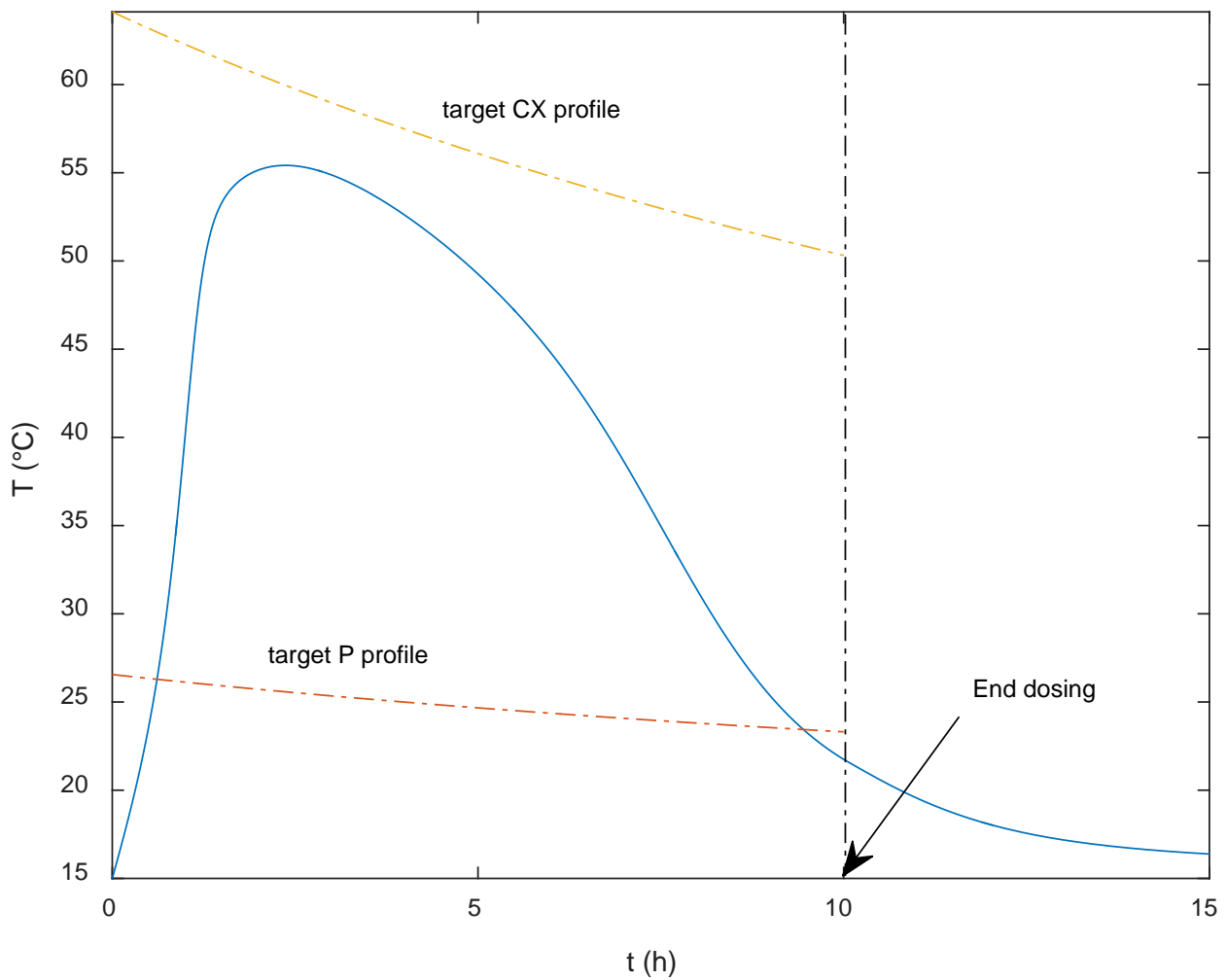

Fig. 8B 


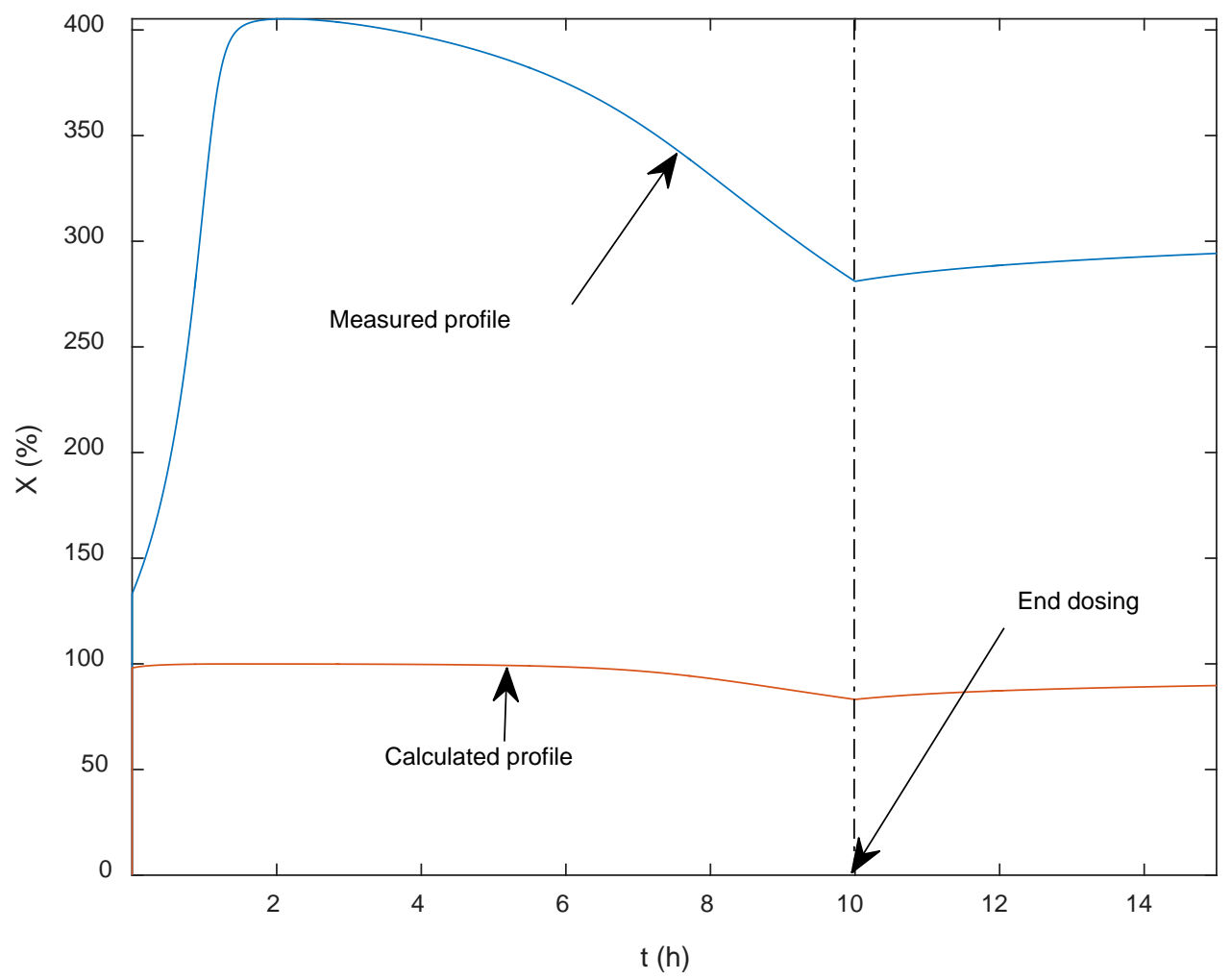

Fig. 8C 


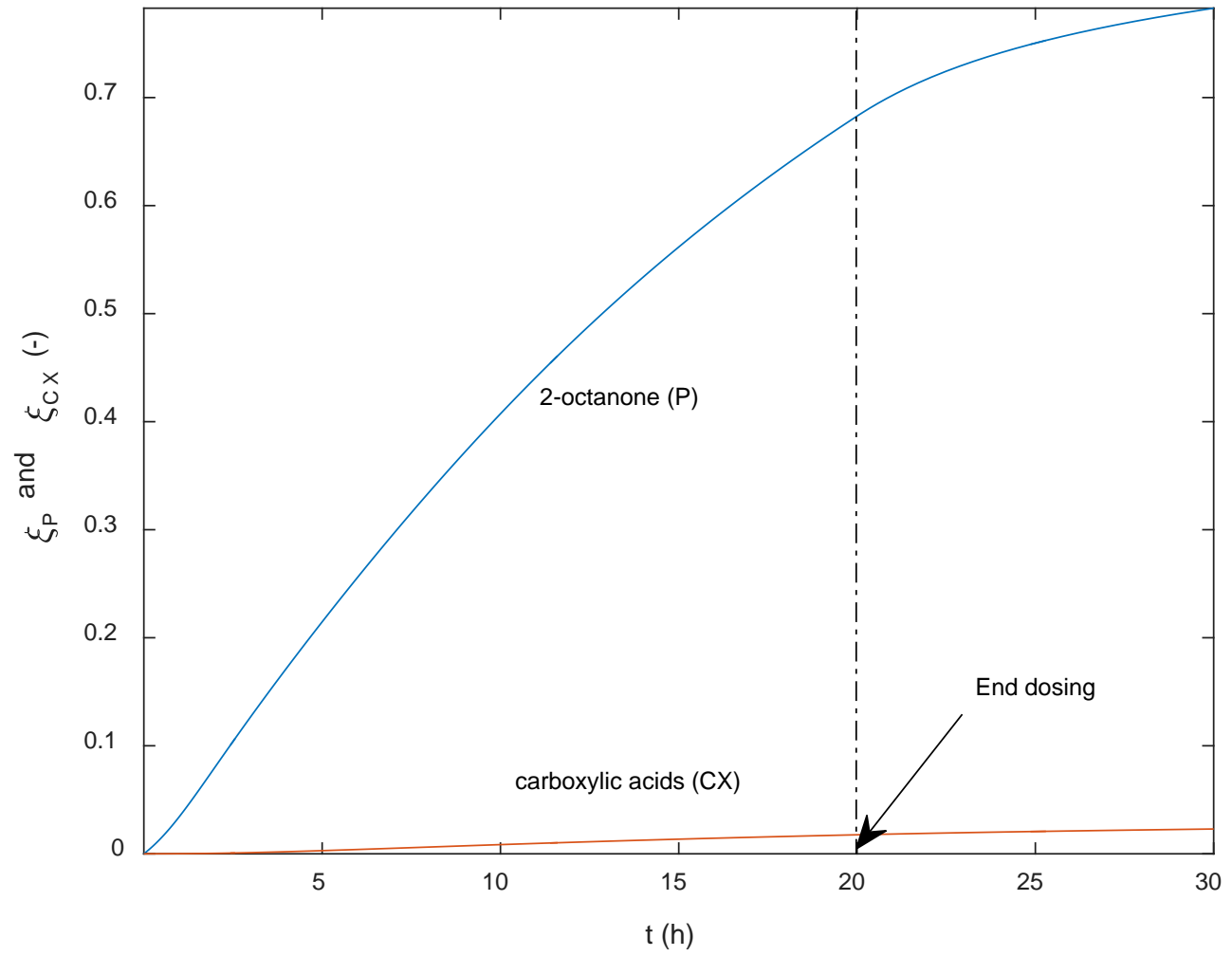

Fig. 9A

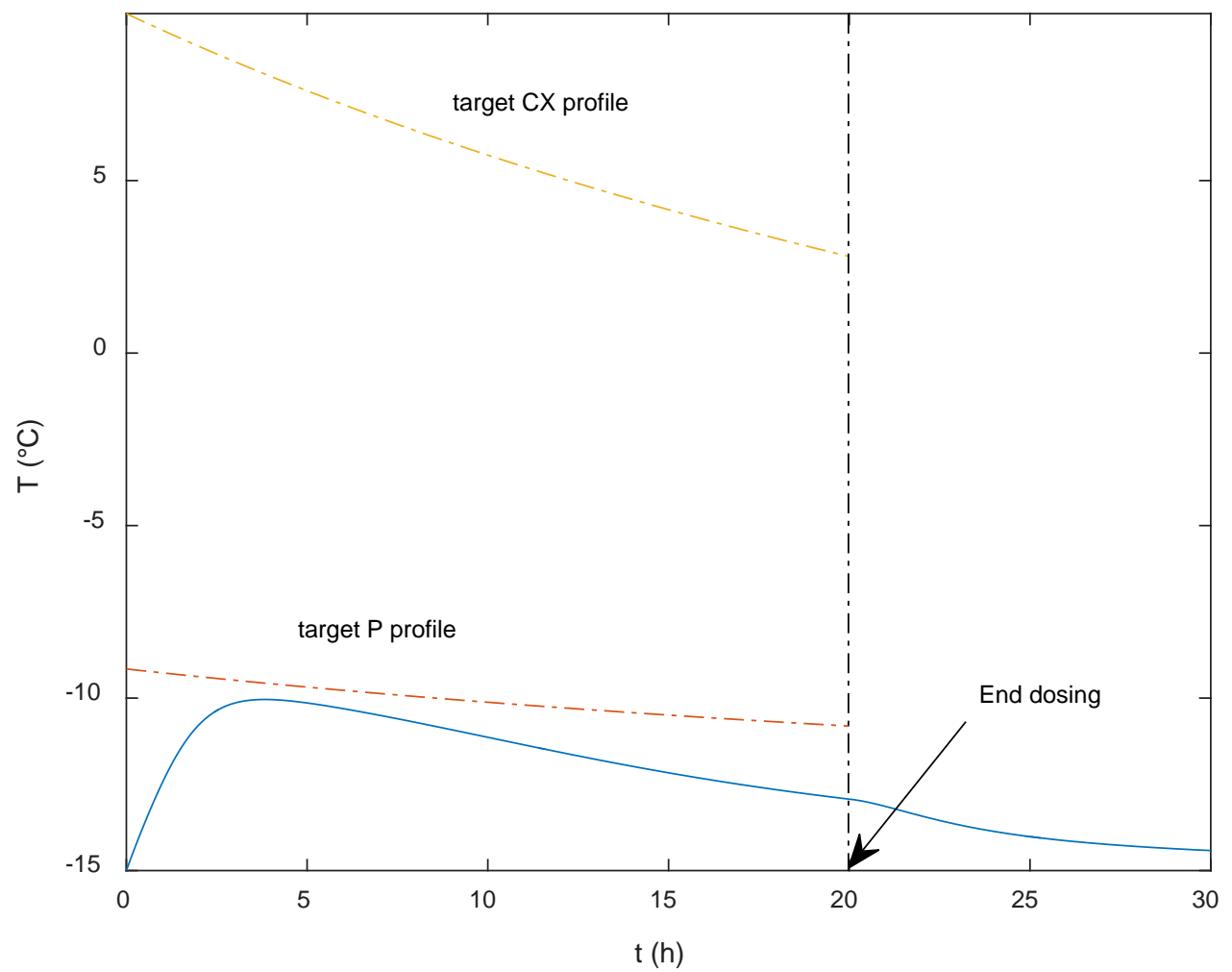

Fig. 9B

41 


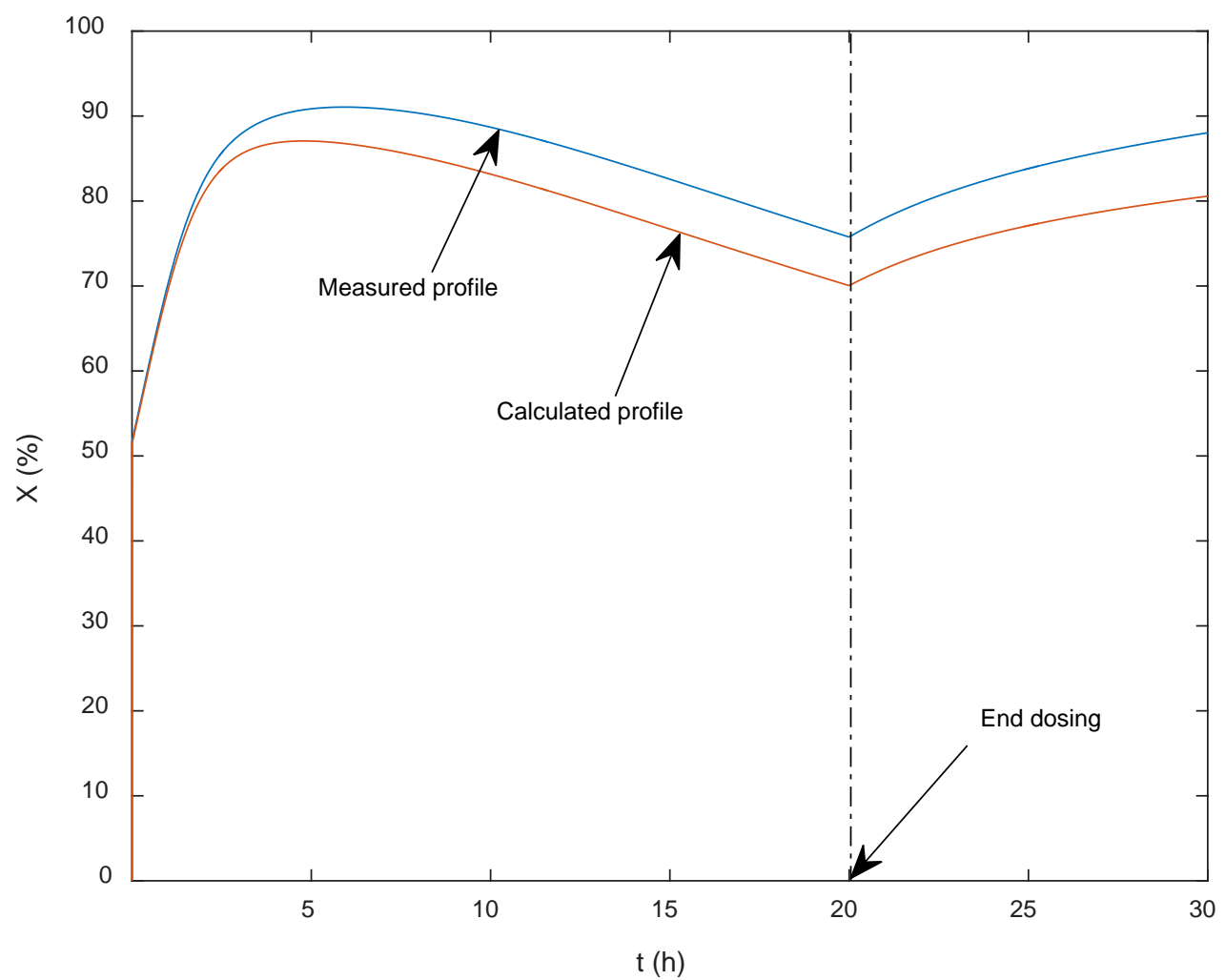

Fig. 9C 


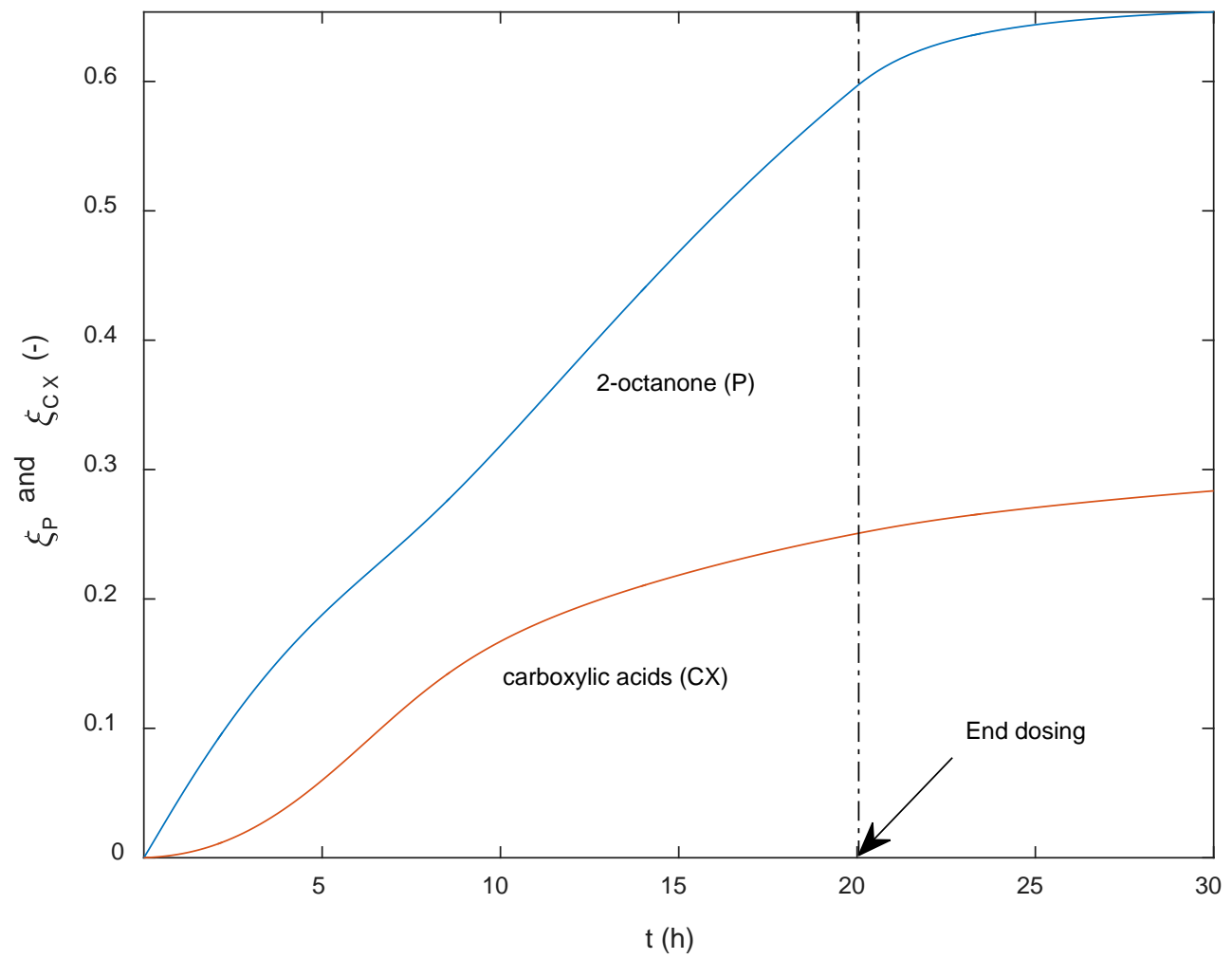

Fig. 10A

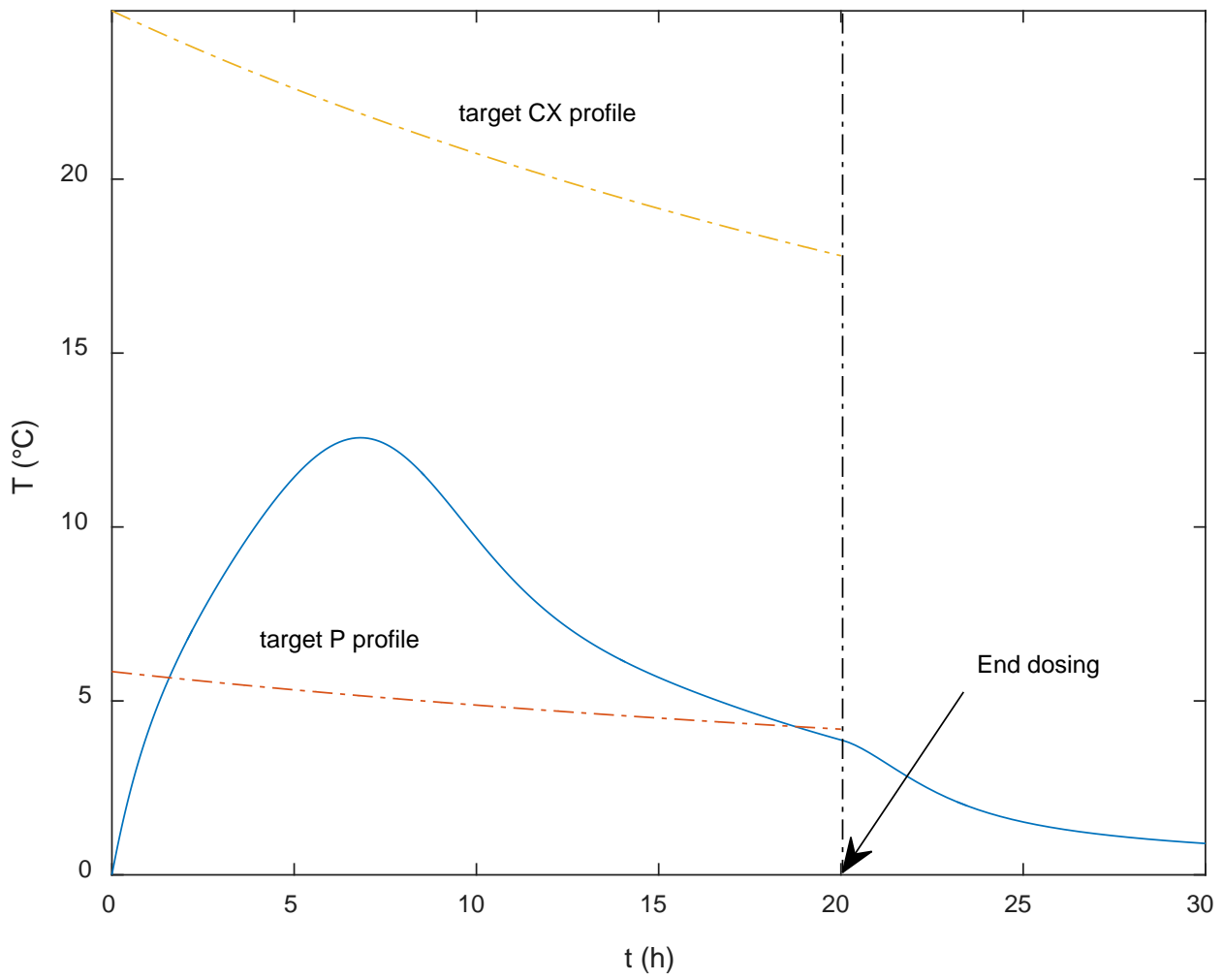

Fig. 10B 


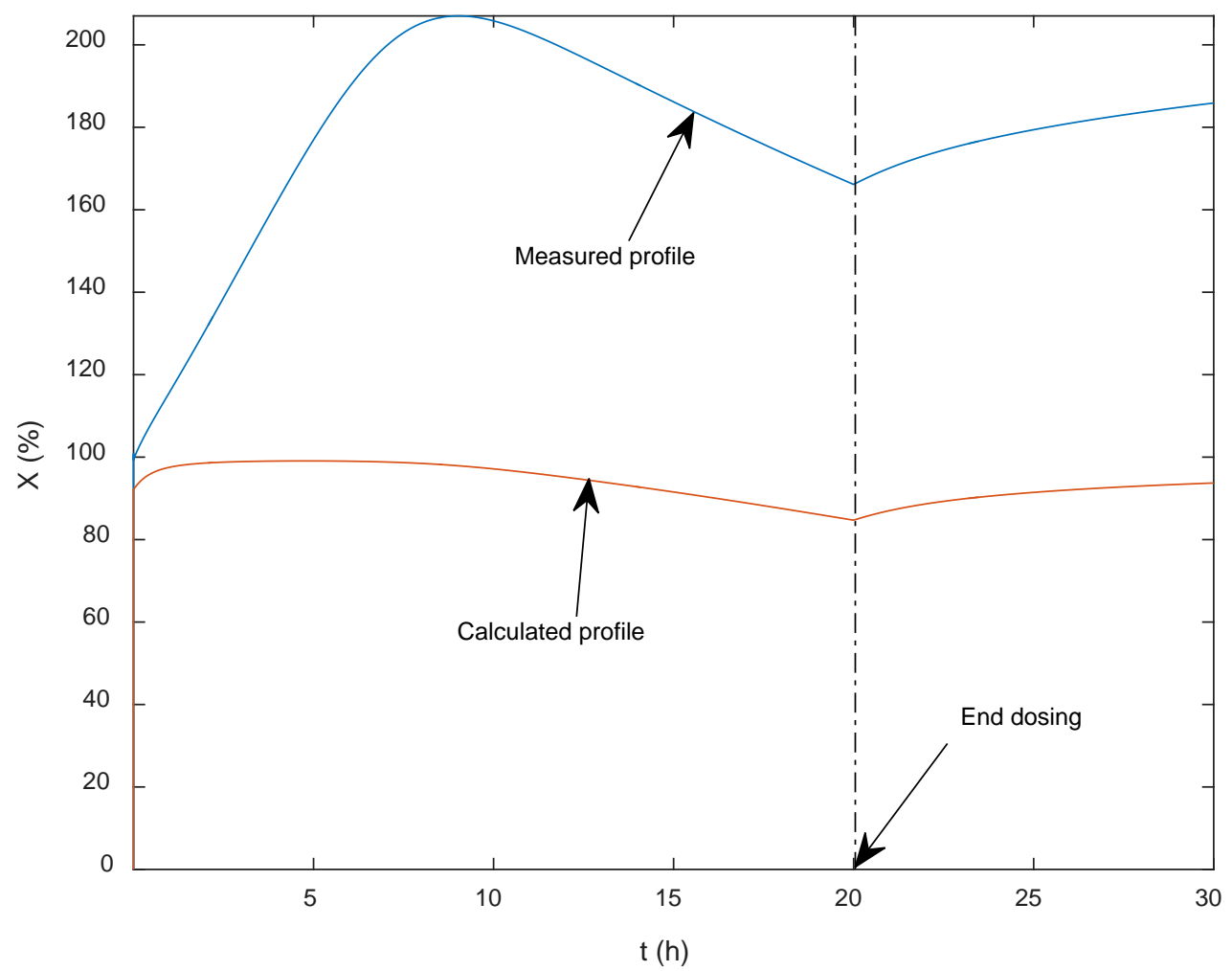

Fig. 10C 


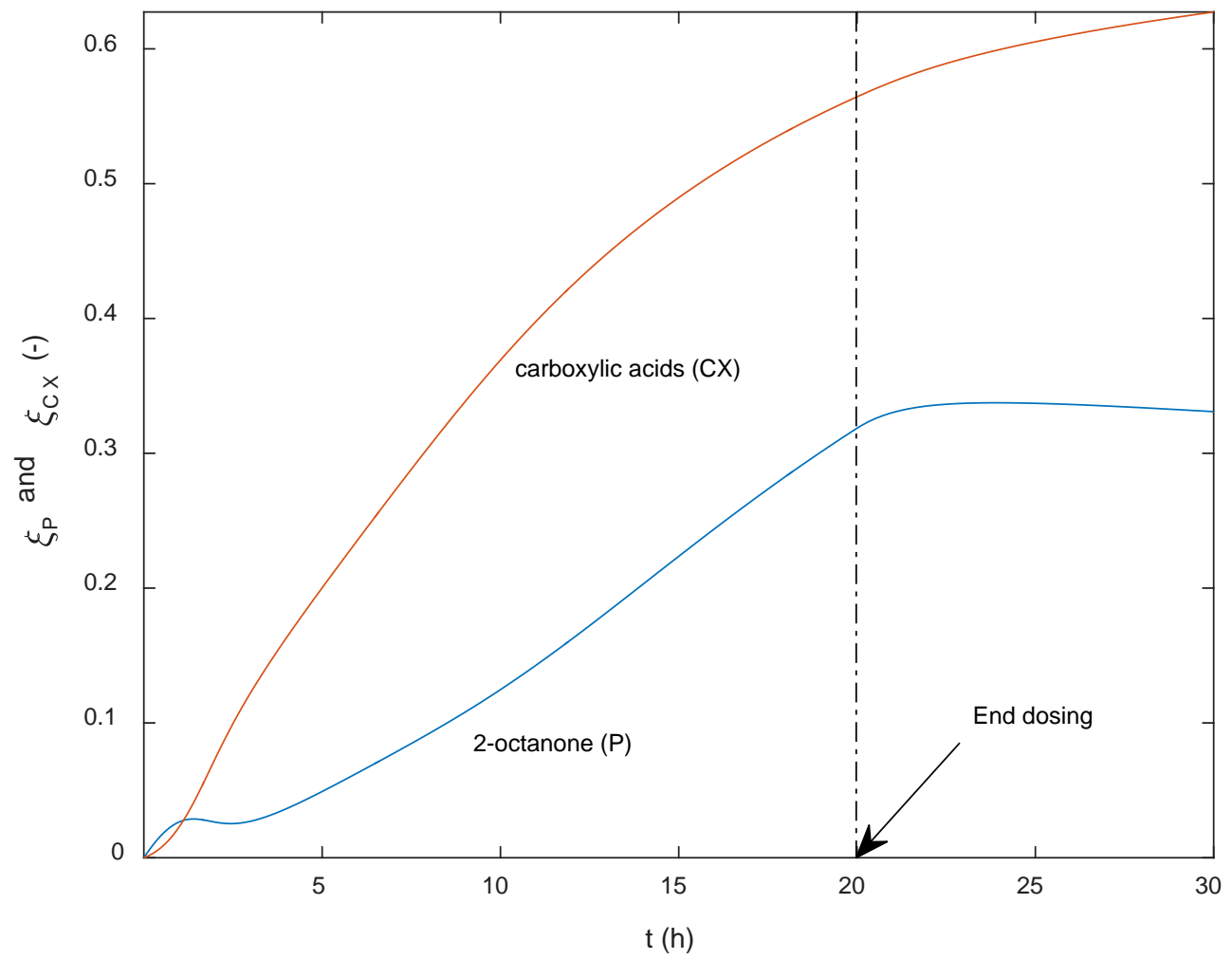

Fig. 11A

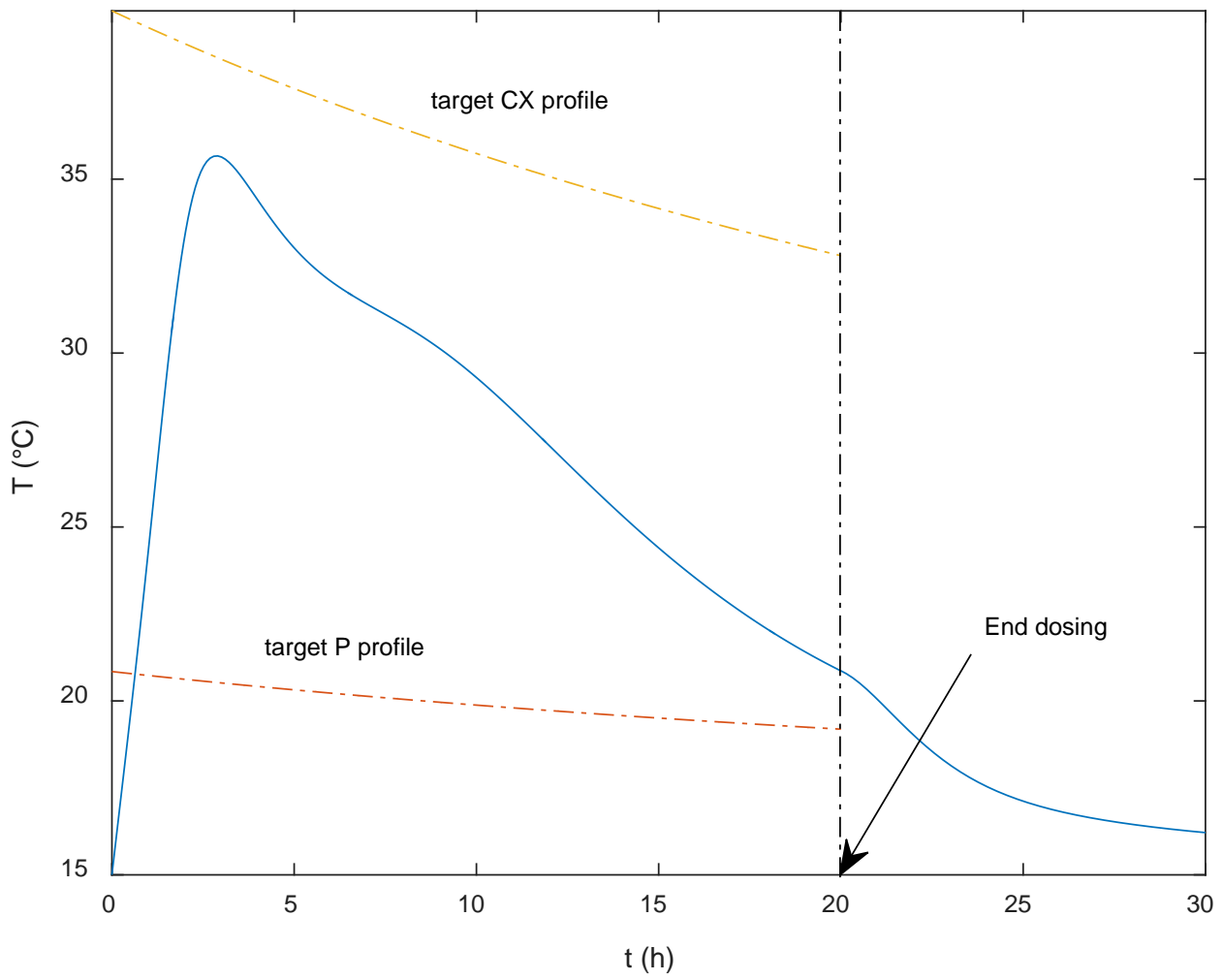

Fig. 11B 


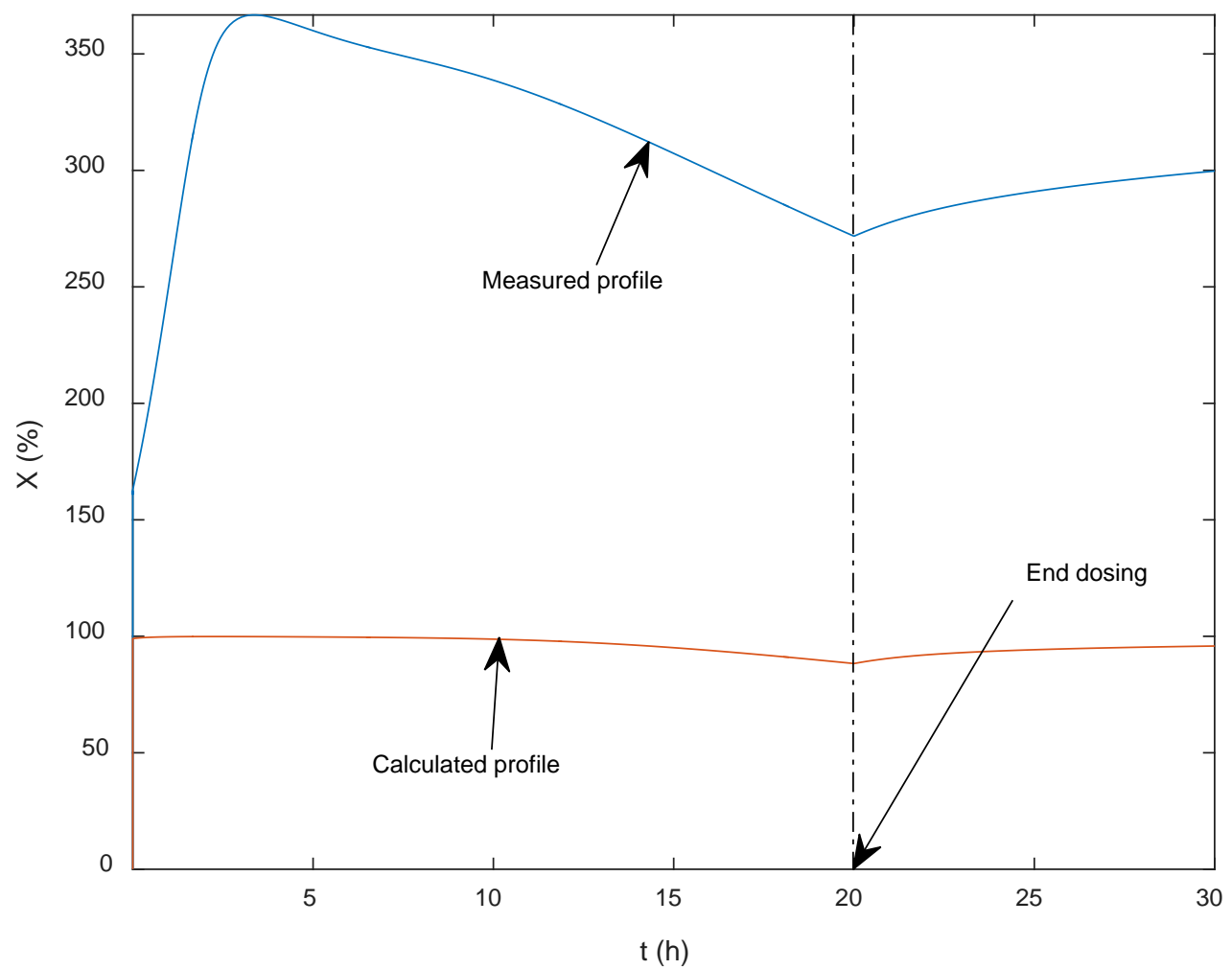

Fig. 11C 


\section{For Table of Contents Only}

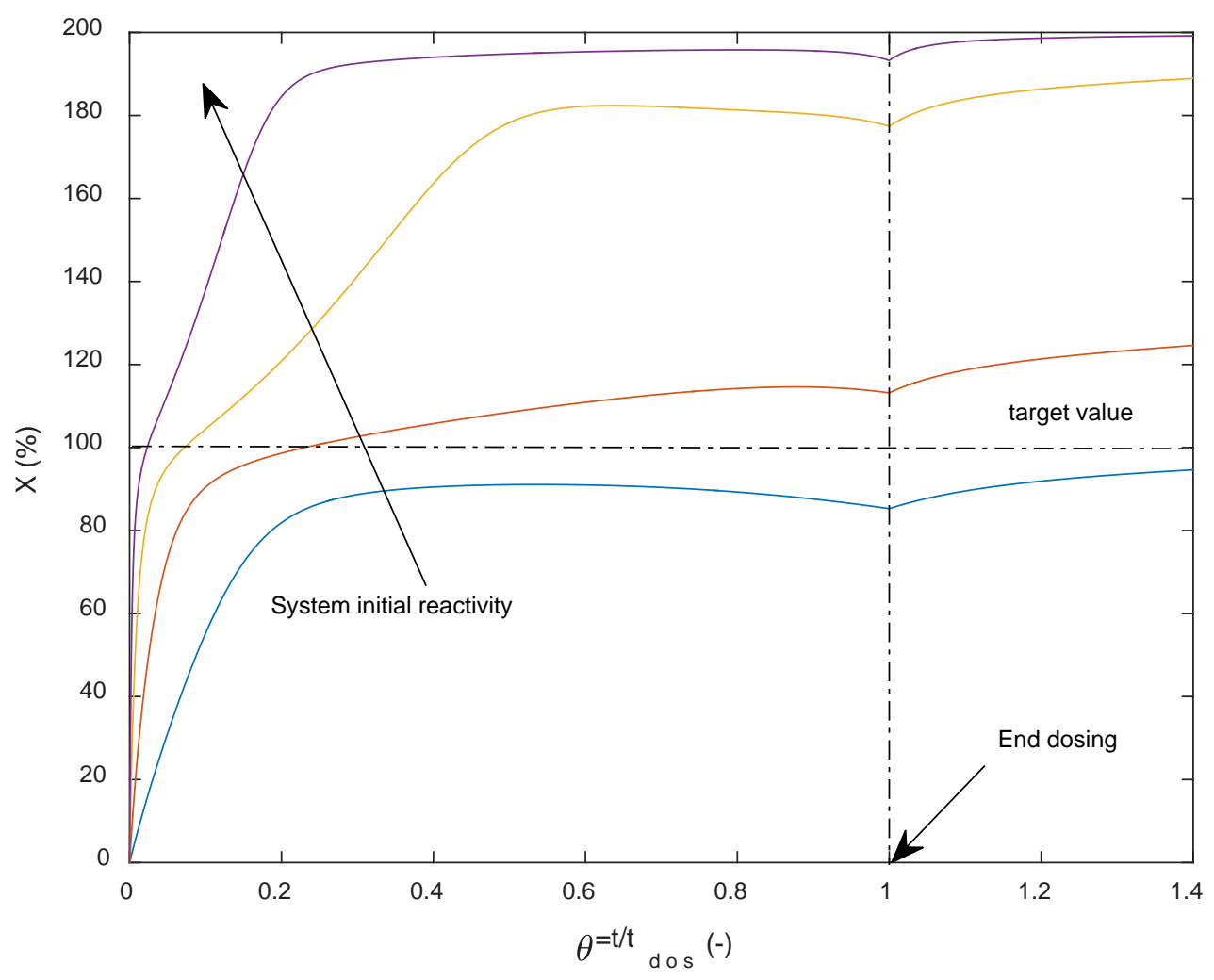

